\title{
Nuclear Optical Model Analysis of Neutron Elastic Scattering for Calcium*
}

\author{
Randall S. Caswell
}

(May 14, 1962)

\begin{abstract}
A nuclear optical model calculation of neutron elastic scattering using five parameters has been made. Appropriate estimates of the effect of compound elastic scattering at low energies are included. Comparisons have been made with experimental data, and results for the parameters adopted are given for elastic scattering in the energy range from 0.734 to 18 Mev. Although reasonably good agreement between the calculation and experimental results have been obtained, there is a discrepancy between experiments below 2 Mev, and experimental data is needed between 6 and $14 \mathrm{Mev}$. Both angular distributions and Legendre expansion coefficients for the total elastic scattering are given.
\end{abstract}

\section{Introduction}

The nuclear optical model has been outstandingly successful in describing the elastic scattering of neutrons and other nuclear particles above the energy of perhaps $6 \mathrm{Mev}$, where compound elastic scattering processes are not important. Below these energies it is necessary to include some estimate of compound elastic scattering. At neutron energies below the first excited state of the target nucleus, inelastic scattering is not possible. In this energy range it is possible to describe the compound elastic scattering by use of the fluctuation cross section [Feshbach, 1960]. Above this energy the angular distribution of the compound elastic scattering may be obtained from the compound statistical model [Hauser and Feshbach, 1952].

Initially in the present work the experimental data was analyzed using the six-parameter nuclear optical model of Bjorklund and Fernbach [1958]. However, it was found that at least as good fits to the experimental data could be obtained with a five-parameter model, using derivative surface absorption instead of an adjustable parameter to determine the width of the imaginary (absorptive) well. This latter model, which contains a Saxon real potential, a Thomas spin-orbit potential, and a surface imaginary potential, was used in this calculation.

This calculation is the first of a series which will provide data in a form suitable for input to neutron penetration calculations with digital computers. The present calculations are for calcium, an important component of concrete which is widely used for neutron shielding. Comparisons with experimental elastic scattering angular distributions are included. Angular distributions and Legendre coefficients for the calculated angular distributions are both presented. The calculations have been programed in Fortran for the IBM 7090 computer at the National Bureau of Standards.

*This work was sponsored by Defense Atomic Support Agency.

\section{Description of the Calculation}

\subsection{Solution of the Wave Equation}

Although the exact phase shift analysis carried out here is standard in many respects, it seems desirable to record the specific method of calculation, including the Legendre polynomial analysis.

We start with the radial part of the non-relativistic Schrödinger wave equation:

$$
\begin{array}{r}
\frac{d^{2} U_{l}(r)}{d r^{2}}+\frac{2 m}{\hbar^{2}}\left[E-\frac{l(l+1) \hbar^{2}}{2 m r^{2}}-(V(r)+i W(r))\right] \\
\times U_{l}(r)=0 .
\end{array}
$$

The potential is described by $V(r)+i W(r)$ where $V(r)$ is the real part of the potential and $W(r)$ is the imaginary part. The wave function $U_{l}(r)$ will also have both real and imaginary parts:

$$
U_{l}(r)=X_{l}(r)+i Y_{l}(r) .
$$

Equation (1) becomes:

$$
\begin{aligned}
\frac{d^{2}\left(X_{l}+i Y_{l}\right)}{d r^{2}}+\frac{2 m}{\hbar^{2}}\left[E-\frac{l(l+1) \hbar^{2}}{2 m r^{2}}\right. & -V-i W] \\
& \times\left(X_{l}+i Y_{l}\right)=0 .
\end{aligned}
$$

Separating this equation into real and imaginary parts, we obtain two coupled real equations which may be solved on the computer.

$$
\begin{aligned}
& \frac{d^{2} X_{l}}{d r^{2}}+\frac{2 m}{\hbar^{2}}\left[E-\frac{l(l+1) \hbar^{2}}{2 m r^{2}}-V\right] X_{l}+\frac{2 m}{\hbar^{2}} W Y_{l}=0 \\
& \frac{d^{2} Y_{l}}{d r^{2}}+\frac{2 m}{\hbar^{2}}\left[E-\frac{l(l+1) \hbar^{2}}{2 m r^{2}}-V\right] Y_{l}-\frac{2 m}{\hbar^{2}} W X_{l}=0
\end{aligned}
$$

These equations are integrated step-by-step outward in radius by the second order Runge-Kutta method [see, for example, Zurmühl, 1961]. The number of 
integration steps is typically 100 to 500. If the wave functions become large, they are automatically renormalized to smaller values by the code. The running time for 15 l's and 200 steps is about 1 min per energy including all angular distributions. The mass appearing in these equations is the reduced mass of the neutron in the neutron-nucleus center-of-mass system. The energy, $E$, is that of the neutron in the center-of-mass system. When the complex potential $(V+i W)$ approaches a non-vanishing constant at the origin, then

$$
U_{l}(r) \rightarrow C_{l} r^{l+1} \text { as } r \rightarrow 0
$$

where $C_{l}$ is a complex number independent of $r$ [Amster, Leshan, and Walt, 1960]. In the presence of the spin-orbit term (see below) there is a $1 / r$ behavior of the potential energy for small values of $r$; however, eq (6) still holds since this term is dominated by the $1 / r^{2}$ dependence of the centrifugal potential [see Bohm, 1951]. Since the cross sections depend only on the logarithmic derivative of the wave function, the normalization is arbitrary and $C_{l}$ can be taken to be any non-zero value. We have chosen $k(1+i)$ for $C_{l}$ where $k$ is a small number chosen to prevent underflow or overflow problems. Provision is made in the code to calculate for values of $l$ up to $l=29$.

For the optical model parameters we have used a potential whose real and imaginary parts are:

$$
\begin{gathered}
\left.V(r)=V_{c} \rho(r)-\alpha V_{c}\left(\frac{\hbar}{2 M c}\right)^{2} \overrightarrow{(l} \cdot \vec{\sigma}\right) \frac{1}{r} \frac{d \rho}{d r}, \\
W(r)=W_{s}\left(4 a \frac{d \rho}{d r}\right)=W_{s}\left(4 \rho^{2} \exp \left[\frac{r-R_{0}}{a}\right]\right)
\end{gathered}
$$

where

$$
\rho(r)=\frac{1}{1+\exp \left[\frac{r-R_{0}}{a}\right]},
$$

the usual "Saxon" potential; $\alpha$ is the strength of the spin-orbit interaction relative to the "Thomas" term for a nucleon; $M$ is the neutron mass; $V_{c}$ is the central real potential; $W_{s}$ is the lowest value of the imaginary surface potential; $\frac{\hbar}{M c}$ is the Compton wavelength for a nucleon; $\vec{l}$ is the orbital angular momentum of the neutron; $\vec{\sigma}$ is the Pauli spin operator of the incident neutron; $R_{0}$ is the nuclear radius; and $a$ is the "diffuseness" parameter of the real potential. If the spin angular momentum of the incident neutron is parallel to the orbital angular momentum of the incident neutron, then $j=l+1 / 2$, and $\vec{\sigma} \cdot \vec{l}=l$. If the spin and orbital angular momentum are anti-parallel, then $j=l-1 / 2$ and $\vec{\sigma} \cdot \vec{l}=$ $-(l+1)$. This leads to two real potentials, $V^{+}(r)$ and $V^{-}(r)$ corresponding to the parallel and antiparallel $\vec{\sigma} \cdot \vec{l}$ interactions. The wave equation is solved for each of these. To obtain the desired cross sections, we need the phase shifts $\eta_{l}^{+}$and $\eta_{l}^{-}$ which measure the effect of the complex potential on the neutron partial waves. These phase shifts are obtained by a calculation which compares the value for logarithmic derivative $f_{l}$ obtained by numerical integration in the presence of the nuclear potential with the corresponding quantity $\left(\Delta_{l}+i S_{l}\right)$ for the zero phase shift spherical Hankel function solutions obtained in the absence of the nuclear potential.

The required expression for $\eta_{\imath}$ is given by Blatt and Weisskopf [1952]:

$$
\eta_{l}=\frac{f_{l}-\Delta_{l}+i S_{l}}{f_{l}-\Delta_{l}-i S_{l}} \exp \left(2 i \xi_{l}\right) .
$$

For neutrons

$$
\exp \left(2 i \xi_{l}\right)=\frac{G_{l}(R)-i F_{l}(R)}{G_{l}(R)+i F_{l}(R)},
$$

where $G_{l}(R)$ and $F_{l}(R)$ are solutions of eq (1) with $(V(r)+i W(r))=0$. In terms of spherical Bessel functions, $F_{l}(x)=x j_{l}(x)$ and $G_{l}(x)=x n_{l}(x)$ where $x=k R$.

\subsection{Evaluation of the Cross Sections Directly From the Nuclear Optical Model}

The total cross section predicted by the nuclear optical model is made up of a shape-elastic scattering cross section and a compound nucleus formation cross section [Feshbach, Porter, and Weisskopf, 1954]:

$$
\sigma_{t}=\sigma_{e}+\sigma_{c}
$$

However, the compound nucleus may decay into the entrance channel producing "compound elastic" scattering or it may produce inelastic scattering or charged particle reactions:

$$
\sigma_{c}=\sigma_{c e}+\sigma_{r}
$$

These equations may now be rearranged to separate the elastic scattering ( $\sigma_{s e}$ and $\sigma_{c e}$ are not distinguishable experimentally) from the reaction cross section:

$$
\sigma_{t}=\left(\sigma_{s e}+\sigma_{c e}\right)+\sigma_{r}=\sigma_{e}+\sigma_{r} .
$$

In the present calculation $\sigma_{c e}$ is estimated by the "fluctuation" cross section, $\sigma_{f l}$, which is important below energies of about $6 \mathrm{Mev}$ :

$$
\sigma_{t}=\sigma_{s e}+\sigma_{f l}+\sigma_{r} .
$$

When inelastic scattering and reactions are zero or negligible, the entire cross section is elastic:

$$
\sigma_{t}=\sigma_{s e}+\sigma_{f l}
$$

In this case the fluctuation cross section may be obtained very simply from the phase shifts of the optical model alone (see Feshbach [1960] for a discussion of the fluctuation cross section). 
We now proceed to evaluate the various cross sections from the calculated phase shifts ( $\eta_{i}$ 's). For both incident particles and the nucleus without spin, the expressions for the incident plane wave, the total wave (which shows the effect of the potential of the nucleus on the incident wave), and the scattered wave are:

$$
\begin{array}{r}
e^{i k z}=\sum_{l=0}^{\infty} i^{l} \frac{2 l+1}{2}\left[h_{l}^{*}(k r)+h_{l}(k r)\right] P_{l}(\cos \theta), \\
\psi_{\text {tot }}(r)=\sum_{l=0}^{\infty} i^{l} \frac{2 l+1}{2}\left[h_{l}^{*}(k r)+\eta_{l} h_{l}(k r)\right] P_{l}(\cos \theta),
\end{array}
$$

and

$$
\begin{aligned}
\psi_{\text {scatt }}(r)= & \psi_{\text {tot }}(r)-e^{i k z} \\
& =\sum_{l=0}^{\infty} i^{l} \frac{2 l+1}{2}\left(\eta_{l}-1\right) h_{l}(k r) P_{l}(\cos \theta) .
\end{aligned}
$$

The incident neutrons which have spin $1 / 2$ may be represented by a plane wave:

$$
\psi_{\text {inc }}=e^{i k z} \chi_{\text {inc }}
$$

where $\chi_{\text {ine }}$ describes the spin wave function of the neutron. $\quad \chi_{\text {inc }}=\left(\begin{array}{l}1 \\ 0\end{array}\right)$ is spin "up." $\quad \chi_{\text {ine }}=\left(\begin{array}{l}0 \\ 1\end{array}\right)$ corresponds to spin "down." In the presence of the nuclear potential the asymptotic form of the wave function of the neutron is:

$$
\psi \underset{r \rightarrow \infty}{\longrightarrow} \psi_{\text {in } \mathrm{e}}+\frac{1}{r} e^{i k r} F(\theta) \chi_{\text {ine }}
$$

where $F(\theta)$ is the scattering matrix.

$$
F(\theta)=A(\theta)+B(\theta) \overrightarrow{\sigma \cdot n}
$$

where $\vec{n}$ is a unit vector perpendicular to the plane of 'scattering. According to the Basel convention [Huber and Meyer, 1961], the positive direction of polarization, given by the unit vector $\vec{n}$, is:

$$
\vec{i}=\frac{\vec{k}_{i} \times \vec{k}_{f}}{\left|\overrightarrow{k_{i}} \times \vec{k}_{f}\right|}
$$

where $\vec{k}_{i}$ and $\vec{k}_{f}$ are the wave vectors of the incident and scattered neutrons.

In the equations above, $h_{l}^{*}=j_{l}-i n_{l}$ and represents an incoming spherical wave and $h_{l}=j_{l}+i n_{l}$ and represents an outgoing spherical wave. To extend this treatment to the case of neutrons with spin incident on spin-zero nuclei [Lepore, 1950], we introduce the operators $\pi_{l}^{+}$and $\pi_{l}^{-}$which select the states for which $j=l+\frac{1}{2}$ and $j=l-\frac{1}{2}$, respectively. These operators are

$$
\pi_{l}^{+}=\frac{l+1+\vec{\sigma} \cdot \vec{l}}{2 l+1} \text { and } \pi_{l}^{-}=\frac{l-\overrightarrow{-\sigma \cdot l}}{2 l+1} .
$$

If $j=l+\frac{1}{2}, \pi^{+}=1, \pi^{-}=0 . \quad$ Jf $j=l-\frac{1}{2}, \pi^{+}=0, \pi^{-}=1$. Applying our operators to the total wave function, eq (16) we have

$$
\begin{aligned}
\psi_{\mathrm{tot}}=\sum_{l=0}^{\infty} \frac{2 l+1}{2} i^{l}\left[\pi^{+}+\pi^{-}\right]\left[h_{l}^{*}(k r)\right. & \left.+\eta_{l} h_{l}(k r)\right] \\
& \times P_{l}(\cos \theta) \chi_{\mathrm{inc} .} .
\end{aligned}
$$

Let $\eta_{l}^{+}$and $\eta_{l}^{-}$be phase shifts corresponding to the parallel and anti-parallel spin-orbit orientations for the neutron. At large radii we use the asymptotic form of the Hankel functions,

$$
\begin{aligned}
\psi_{\mathrm{tot}}=\sum_{l=0} & \frac{(2 l+1) i^{l}}{2 k r}\left\{\pi _ { l } ^ { + } \left(\eta_{l}^{+} e^{i\left[k r-(l+1) \frac{\pi}{2}\right]}\right.\right. \\
+ & \left.e^{-i\left[k r-(l+1) \frac{\pi}{2}\right]}\right)+\pi_{l}^{-}\left(\eta_{l}^{-} e^{i\left[k r-(l+1) \frac{\pi}{2}\right]}\right. \\
& \left.\left.+e^{-i\left[k r-(l+1) \frac{\pi}{2}\right]}\right)\right\} \times P_{l}(\cos \theta) \chi_{\mathrm{inc} .}
\end{aligned}
$$

If we now subtract the incident wave from the total wave to obtain the scattered wave, we find

$$
\begin{aligned}
& \psi_{\text {seatt }}=\sum_{l=0}^{\infty} \frac{e^{i k r}}{2 i k r}\left[(l+1)\left(\eta_{l}^{+}-1\right)+l\left(\eta_{l}^{-}-1\right)\right. \\
& \left.+\left(\eta_{l}^{+}-\eta_{l}^{-}\right) \overrightarrow{\sigma \cdot l}\right] P_{l}(\cos \theta) \chi_{\mathrm{inc}},
\end{aligned}
$$

where we have used the expressions (17a) for the operators and the condition that when $\eta_{l}^{+}=\eta_{l}^{-}=1$, $\psi_{\text {scatt }}$ must equal zero. The right-left asymmetry in the scattering of a polarized beam is introduced through the $\overrightarrow{(\sigma} \cdot \vec{l})$ operator:

$$
\overrightarrow{(\sigma \cdot l)} P_{l}(\cos \theta)=\vec{\sigma} \cdot\left[\vec{n}\left(-i \frac{\partial}{\partial \theta}\right) P_{l}(\cos \theta)\right] .
$$

However, $\frac{\partial}{\partial \theta}=-\sin \theta \frac{\partial}{\partial(\cos \theta)}$. Finally,

$$
\left.(\vec{\sigma} \cdot \vec{l}) P_{l}(\cos \theta)=\overrightarrow{(\sigma} \cdot \vec{n}\right)\left[i \sin \theta \frac{\partial}{\partial(\cos \theta)} P_{l}(\cos \theta)\right],
$$

$$
(\vec{\sigma} \cdot \vec{l}) P_{l}(\cos \theta)=\overrightarrow{(\sigma \cdot \vec{n})} i P_{l}^{1}(\cos \theta)
$$

where $P_{l}^{1}(\cos \theta)=\sin \theta \frac{\partial}{\partial(\cos \theta)} P_{l}(\cos \theta)$. Note: a $(-1)^{m}$ term is sometimes included in the definition of the associated Legendre function $P_{l}^{m}(\cos \theta)$, in which case our function has the opposite sign, and a minus sign appears on the right side of eq (21). $A(\theta)$ and $B(\theta)$ appearing in the scattering matrix, eq (16) are:

$$
A(\theta)=\frac{1}{2 i k} \sum_{l=0}^{\infty}\left[(l+1)\left(\eta_{l}^{+}-1\right)+l\left(\eta_{l}^{-}-1\right)\right] P_{l}(\cos \theta)
$$




$$
B(\theta)=\frac{1}{2 k} \sum_{l=1}^{\infty}\left[\eta_{l}^{+}-\eta_{l}^{-}\right] P_{l}^{1}(\cos \theta) .
$$

The differential scattering cross section is

$$
\frac{d \sigma}{d \Omega}=\frac{1}{2} \operatorname{tr} F^{+} F=|A|^{2}+|B|^{2} .
$$

The polarization is given by

$$
P=\frac{2 \operatorname{Re}\left(A^{*} B\right)}{|A|^{2}+|B|^{2}} .
$$

For a completely polarized incident beam with spin "up," $P=(L-R) /(L+R)$, where $L$ and $R$ are the measured left and right detector counting rates.

The total, compound nucleus formation, and shape elastic cross sections (integrated over angle) are:

$$
\begin{aligned}
& \sigma_{t}=\frac{\pi}{k^{2}} \sum_{l=0}^{\infty}\left[(l+1) 2 \operatorname{Re}\left(1-\eta_{l}^{+}\right)+l 2 \operatorname{Re}\left(1-\eta_{l}^{-}\right)\right] \\
& \sigma_{c}=\frac{\pi}{k^{2}} \sum_{l=0}^{\infty}\left[(l+1)\left(1-\left|\eta_{l}^{+}\right|^{2}\right)+l\left(1-\left|\eta_{l}^{-}\right|^{2}\right)\right] \\
& \sigma_{s e}=\frac{\pi}{k^{2}} \sum_{l=0}^{\infty}\left[(l+1)\left|1-\eta_{l}^{+}\right|^{2}+l\left|1-\eta_{l}^{-}\right|^{2}\right] .
\end{aligned}
$$

For use in inelastic scattering calculations and in our estimate of compound elastic scattering, the "transmission coefficients" are also calculated:

$$
T_{l}^{+}=\left(1-\left|\eta_{l}^{+}\right|^{2}\right) \text { and } T_{l}^{-}=\left(1-\left|\eta_{l}^{-}\right|^{2}\right) .
$$

\subsection{Compound Elastic Scattering}

Whereas shape elastic scattering is given directly by the nuclear optical model, our estimate of compound elastic scattering is treated in four different ways depending upon the incident neutron energy. Below $3.35 \mathrm{Mev}$, it may be obtained from the optical model phase shifts, with a small correction for the
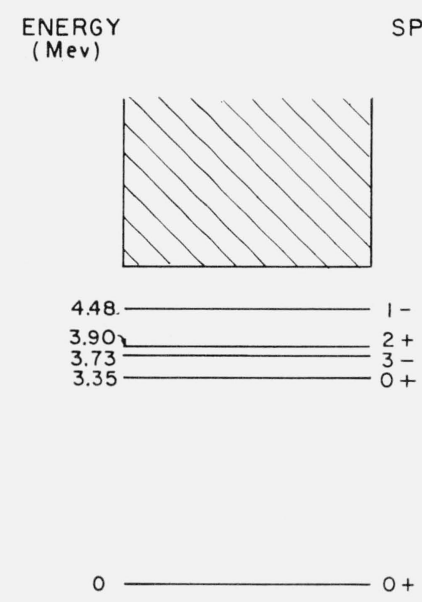

Figure 1. Low-lying energy levels of $\mathrm{Ca}^{40}$.

Spins and parities in parentheses are taken from Troubetzkoy, Kalos, Lustig, Ray, and Trupin [1961]. Levels taken as a continuum above' 5 Mev, observed $(n, p)$ cross section. In the energy range from 3.35 to $5.0 \mathrm{Mev}$, a Hauser-Feshbach [1952] hand calculation using discrete energy levels of the target nucleus (see fig. 1) was made. From 5.0 to 5.7 Mev a Hauser-Feshbach calculation using a statistical-model residual nucleus was made. In this case the compound elastic scattering is isotropic because of the randomness of the spins and parities of the levels assumed in the statistical model. The angular isotropy has been proved by Wolfenstein [1951] and by Hauser and Feshbach. Above $6 \mathrm{Mev}$ compound elastic scattering is neglected.

The fluctuation cross section, in the absence of inelastic scattering and reactions, may be obtained from the phase shifts of the optical model [Feshbach, 1960]:

$$
\begin{aligned}
&|A|_{f l}^{2}= \frac{1}{4 k^{2}} \sum_{l=0}^{\infty}\left\{(l+1)^{2}\left(1-\left|\eta_{l}^{+}\right|^{2}\right)^{2}+l^{2}\left(1-\left|\eta_{l}^{-}\right|\right)^{2}\right\} \\
& \times\left[P_{l}(\cos \theta)\right]^{2} \\
&|B|_{f l}^{2}=\frac{1}{4 k^{2}} \sum_{l=1}^{\infty}\left\{\left(1-\left|\eta_{l}^{+}\right|^{2}\right)+\left(1-\left|\eta_{l}^{-}\right|^{2}\right)\right\}\left[P_{l}^{1}(\cos \theta)\right]^{2} .
\end{aligned}
$$

At energies below the energy of the first excited state in the target nucleus $\left(3.35 \mathrm{Mev}\right.$ for $\left.\mathrm{Ca}^{40}\right)$, we have used eq (30) to calculate the compound elastic scattering. Note that this leads not to isotropic scattering but to an angular distribution which goes predominantly as $\left[P_{l}(\cos \theta)\right]^{2}$ for neutrons of angular momentum $l$.

The cross section for inelastic scattering of a neutron of incident angular momentum $l$, final angular momentum $l^{\prime}$, from a nucleus of initial angular momentum $i$ and final angular momentum $i^{\prime}$ is given by Hauser and Feshbach as

$$
\sigma\left(l, i \mid l^{\prime}, i^{\prime}\right)=\frac{1}{2(2 i+1)} \sum_{\alpha, \beta} \sigma\left(l, j_{\alpha}\left|l^{\prime}, j_{\beta}^{\prime}\right| \theta\right)
$$

where

$$
\begin{aligned}
\sigma\left(l, j\left|l^{\prime}, j^{\prime}\right| \theta\right)=\frac{\pi}{k^{2}}(2 l+1) & T_{l}(E) \sum_{J} \\
& \frac{A_{J}\left(l, j\left|l^{\prime}, j^{\prime}\right| \theta\right)}{1+\sum_{p, q, r}^{\prime} T_{p}\left(E_{q}^{\prime}\right) / T_{l}^{\prime}\left(E^{\prime}\right)},
\end{aligned}
$$

and is the cross section for production of neutrons of energy $E^{\prime}$ of angular momentum $l^{\prime}$, channel spin $j^{\prime}$, moving in a direction $\theta$. The $r$ index refers to possible channel spins, $p$ to possible final neutron angular momenta, $E_{q}^{\prime}$ to final neutron energies. $J$ is the total angular momentum of the compound nucleus state. The prime on the summation indicates that we omit the term referring to the final neutron $E^{\prime}, l^{\prime}, j^{\prime}$ we are considering. As we shall see the denominator of eq (32) is essentially the branching ratio of the specific neutron transition under consideration versus all other possibilities. If we immediately specialize to the case of compound elastic scattering, $\left(E=E^{\prime}, l=l^{\prime}, j=j^{\prime}\right)$, consider spin zero nuclei only $\left(j=j^{\prime}=\frac{1}{2}, i=0\right.$, and $\left.J=l \pm \frac{1}{2}\right)$, and $T_{l}$ 's as defined in eq (29), the angular distribution for the $l$ th partial wave of compound elastically scattered 
neutrons becomes:

$$
\begin{array}{r}
\left(\frac{d \sigma}{d \Omega}\right)_{l_{C E}}=\frac{\pi}{2 k^{2}}\left\{\frac{(l+1) T_{l}^{+}(E)}{1+\sum_{p, q, r}^{\prime} T_{P}^{+}\left(E_{q}^{\prime}\right) / T_{l}^{+}(E)}\right. \\
A_{l+\frac{1}{2}}\left(l, \frac{1}{2}\left|l, \frac{1}{2}\right| \theta\right)+\frac{l T_{l}^{-}(E)}{1+\sum_{p, q, r}^{\prime} T_{P}^{+}\left(E_{q}^{\prime}\right) / T_{l}^{-}(E)} \\
\left.A_{l-\frac{1}{2}}\left(l, \frac{1}{2}\left|l, \frac{1}{2}\right| \theta\right)\right\} .
\end{array}
$$

The $A$-functions that occur in eq (33) are easily expressed in terms of $Z$-coefficients used by Blatt and Biedenharn [1952] and tabulated by Biedenharn [1953]:

$$
A_{J}(l, j|l, j| \theta)=\frac{1}{4 \pi(2 l+1)} \sum_{L}[Z(l J l J ; j L)]^{2} P_{L}(\cos \theta) .
$$

The question of phases does not enter since the $Z$ coefficient appears only when squared. Note that these results appear naturally in a Legendre series expansion which may be easily combined with the Legendre coefficient expansion as determined by the computer for the shape elastic scattering. Equations (33) and (34) are used to calculate the region of discrete states of the target nucleus (3.35 to 5 $\mathrm{Mev})$. A correction to the branching ratio appearing. in eq (33) is applied to allow for experimentally observed reaction cross sections. From 5 to 5.7 $\mathrm{Mev}$, the residual nucleus is considered as statistical, and the compound elastic scattering is isotropic.

\subsection{Legendre Coefficient Analysis of the Elastic Scattering}

The elastic scattering angular distribution is represented in the following way:

$\frac{d \sigma}{d \Omega}(E, \theta)=\frac{\sigma_{\text {total elastic }}}{4 \pi} \sum_{l}(2 l+1) S_{l}(E) P_{l}(\cos \theta)$

where $S_{0}(E)=1$.

The differential cross section as obtained from eq (24) appears as a sum of the products of two series:

$$
\begin{aligned}
\frac{d \sigma}{d \Omega}=\sum_{l} A_{l} P_{l}( & (\cos \theta) \sum_{m} A_{m} P_{m}(\cos \theta) \\
& +\sum_{l} B_{l} P_{l}^{1}(\cos \theta) \sum_{m} B_{m} P_{m}^{1}(\cos \theta) .
\end{aligned}
$$

The first term in eq (36) may be represented by a single series of Legendre coefficients

$$
\frac{d \sigma}{d \Omega}=\sum_{k} a_{k} P_{k}(\cos \theta),
$$

where $a_{k}$ is given by

$$
\begin{array}{r}
a_{k}=\sum_{l=0} \sum_{m=0} A_{l} B_{m} \frac{C_{\frac{1}{2}(l-m+k)} C_{\frac{1}{2}(l+m-k)} C_{\frac{1}{2}(m-l+k)}}{C_{\frac{1}{2}(l+m+k)}} \\
\times \frac{2 k+1}{l+m+k+1},
\end{array}
$$

where $C_{j}=\frac{1.3 .5 \ldots(2 j-1)}{j !} ; l, m$ are positive integers; $(l+m+k)$ is even; and $|l-m| \leq k \leq l+m$, that is, the three vectors satisfy the "triangle condition" [Whittaker and Watson, 1958].

The product of the two series in $P_{l}^{1}(\cos \theta)$ can be reduced to product of two series in $P_{l}(\cos \theta)$ which can then be solved by eq (38). First we express the $P_{l}^{1}(\cos \theta)$ 's in terms of polynomial expansions in $P_{l}(\cos \theta)$ [see Morse and Feshbach, 1953]:

$$
P_{l}^{1}(\cos \theta)=\frac{l(l+1)}{(2 l+1) \sin \theta}\left[P_{l-1}(\cos \theta)-P_{l+1}(\cos \theta)\right]
$$

$P_{m}^{1}(\cos \theta)=\sin \theta\left[(2 m-1) P_{m-1}(\cos \theta)\right.$

$$
\begin{aligned}
& \quad+(2 m-5) P_{m-3}(\cos \theta) \\
& \left.\quad+(2 m-9) P_{m-5}(\cos \theta)+\ldots\right]
\end{aligned}
$$

Any product term $P_{l}^{1}(\cos \theta) P_{m}^{1}(\cos \theta)$ resulting from the series product in eqs (36) may be expressed in terms of a product of expressions from eqs (39) and (40). Note that in the product $\sin \theta$ cancels out, leaving only terms in Legendre polynomials. Relations (38 to 40) were programed for the computer so that a Legendre coefficient analysis of the form of eq (35) could be directly obtained from the calculated phase shifts.

The calculation could equally well be done through use of vector-coupling coefficients [Edmonds, 1957]. It is expected that the problem for the computer would be about the same either way. The $C_{j}$ coefficients used here are closely related to the ClebschGordan coefficient $(a b 00 \mid a b c 0)$ as given in eq (5) of Blatt, Biedenharn, and Rose [1952].

\section{Choice of Optical Model Parameters and Comparison With Experiment}

Calcium is composed of 96.97 percent $\mathrm{Ca}^{40}$ with 2.06 percent of $\mathrm{Ca}^{44}$, and smaller amounts of $\mathrm{Ca}^{42}$, $\mathrm{Ca}^{43}, \mathrm{Ca}^{45}$, and $\mathrm{Ca}^{46}$. In this calculation it is considered as pure $\mathrm{Ca}^{40}$ except that a slightly larger value of $R_{0}$ is used to approximate the effect of the other isotopes.

In the initial attempts to fit calcium neutron cross section data, the model of Bjorklund and Fernbach [1958] was used. The real potential is as described by eq (7), and the imaginary potential is a Gaussian absorption located at the surface:

$$
W=W_{s} \exp \left[-\left(\frac{r-R_{0}}{b}\right)\right]^{2}
$$


This model, which has been quite successful in fitting neutron elastic scattering data at 4.1, 7, and $14 \mathrm{Mev}$, involves six parameters: $R_{0}, V_{c}, \alpha, a, W_{s}$, and $b$. In attempting to fit this data, $R_{0}$ was held constant at $1.25 \mathrm{~A}^{1 / 3}$ fermis, $b$ at 0.980 fermis, $\alpha$ at 35 . The average atomic weight was used for $\mathrm{A}$. The other three parameters were varied. A problem of the optical model is the large number of arbitrary parameters. In an attempt to reduce the number of parameters, the width of the surface absorption, $b$, was eliminated as an independent parameter and derivative surface absorption used instead as given in eq (8). Somewhat surprisingly the agreement with the experimental data was considerably improved at $14.6 \mathrm{Mev}$, and was equally good at the energies of $2 \mathrm{Mev}$ and below where data existed which could be directly compared with optical model predictions using the fluctuation cross section. The improved agreement at $14.6 \mathrm{Mev}$ may be stated in another way; namely, the value of $b$ $(0.980$ fermis $)$ is too small at this energy, and a thicker shell of surface absorption of neutrons should be used. This is given automatically by the use of a derivative surface absorption.

Using the derivative surface absorption model, $R_{0}$ was held constant at $1.25 \mathrm{~A}^{1 / 3}$ fermis, the value indicated by the work of Bjorklund and Fernbach, and also by the optical model analyses of proton polarization reported by Gursky and Stewart [1961]. Actually the parameters $V_{c}$ and $R_{0}$ act very much like a single parameter $V_{c} R_{0}{ }^{n}$ where $n$ is equal to 2 at low energies and increases slightly with energy. Our choice is to hold $R_{0}$ fixed and vary $V_{c}$. The strength of the spin-orbit coupling, $\alpha$, was also held at the value of 35 used by Bjorklund and Fernbach because it was felt that changes or improvements in this value should come from the analysis of polarization data to which $\alpha$ is more sensitive, rather than angular distribution data which is considered here. Three parameters were allowed to vary, $V_{c}, W_{\mathrm{s}}$, and a. Although $a$ could have been held fixed, independent of energy, at a value of about 0.580 fermis to obtain fairly good fits to the experimental data everywhere, it was found that better fits were obtained if $a$ was taken as 0.600 fermis at $14.6 \mathrm{Mev}$ and at 0.550 fermis below $2 \mathrm{Mev}$. Smooth curves drawn through the data were used to obtain parameters for the optical model calculations, even though local variations sometimes gave better fits (see fig. 2). This apparent jumping around of the experimental data is due at the low energies to the presence of resonances in the cross section, which the optical model averages over.

It should also be mentioned that a calculation which predicts the energy variation of the parameters of the optical model by use of a nonlocal potential has been made by Perey and Buck [1961]. The predictions of Perey and Buck have not been used here since it seemed unlikely that they would improve the cross section data.

Experimental data used for the parameter determination at $14.6 \mathrm{Mev}$ were taken from Cross and Jarvis [1960]; below $2 \mathrm{Mev}$, the data of Seagrave, Cranberg, and Simmons [1958] and Lane, Langs- dorf, Monahan, and Elwyn [1960] as collected by Howerton [1961] were used. Comparison of the calculation to experimental data is shown in figures 3 through 12. Comparison is also made to data at

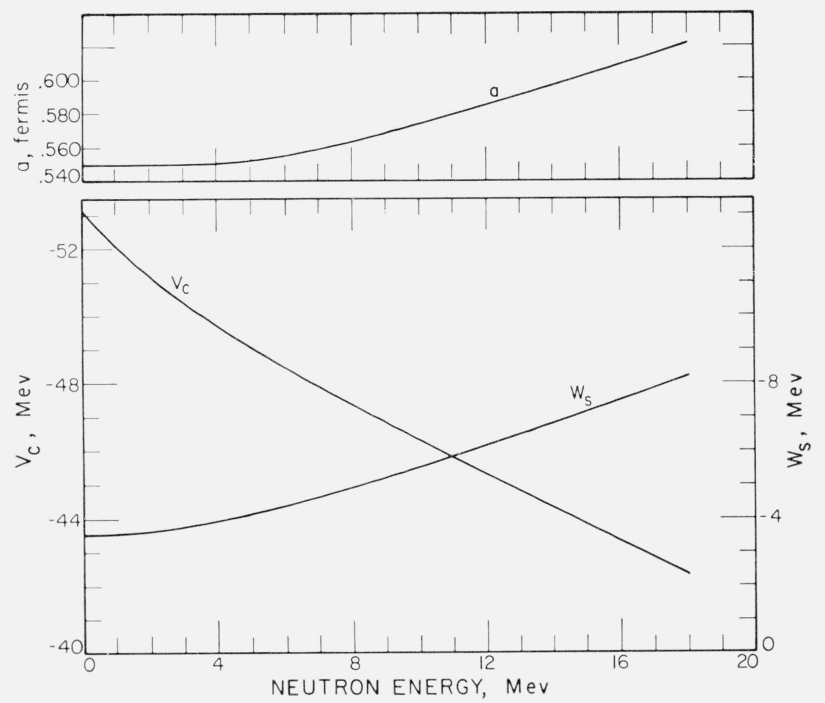

FIGURE 2. Optical model parameters versus energy as adopted for the calculation.

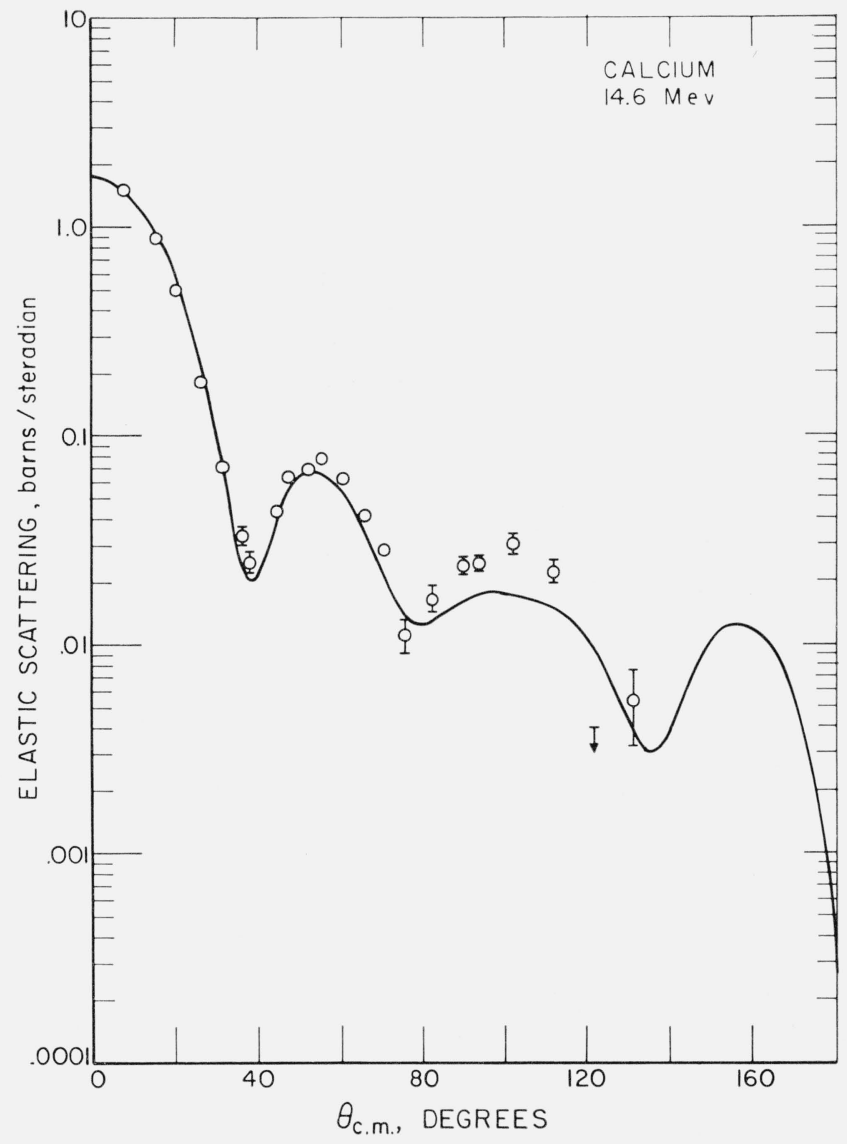

Figure 3. Elastic scattering at $14.6 \mathrm{Mev}$.

Experimental data are those of Cross and Jarvis [1960]. The curves in this and succeeding figures are from this calculation using the optical model parameters of figure 2 . 


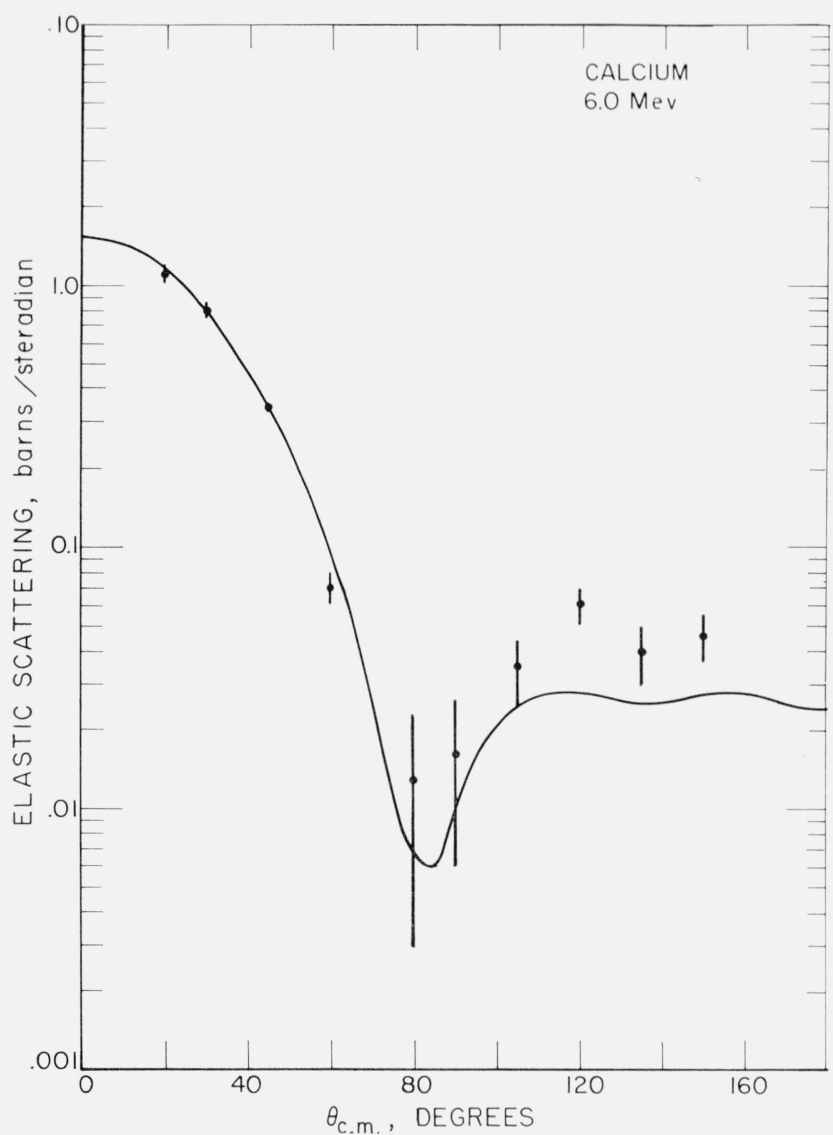

Figure 4. Elastic scattering at $6.0 \mathrm{Mev}$.

Experimental data are from Seagrave, Cranberg, and Simmons [1958].

4.1 Mev of Vincent, Morgan, and Prud'homme [1960] and to an angular distribution of Seagrave, Cranberg, and Simmons [1958] at 6.0 Mev. Neither of these distributions was used to obtain the optical model fit because the Hauser-Feshbach hand calculation involved made parameter fitting quite difficult (it later turned out that at $6.0 \mathrm{Mev}$ the compound elastic scattering could be neglected). Nevertheless the agreement between calculation and experiment is about the same here as at the other energies. We may therefore be reasonably confident that the calculation predicts the cross sections quite well where they have not been measured.

It would not be possible for these calculations to agree with both the Seagrave et al. and the Lane et al. experimental measurements, since these disagree with each other. In general the angular distributions of Lane et al. are more isotropic, while the distributions of Seagrave et al. have a larger cross section in the forward direction. Somewhat more weight was given to the Seagrave et al. experiment, since the geometry appears to be somewhat cleaner and less subject to multiple scattering effects which would tend to make the distributions too isotropic.

This optical model underestimates the magnitude of the non-elastic (or compound nucleus formation) cross section at $14.5 \mathrm{Mev}$. The calculation gives

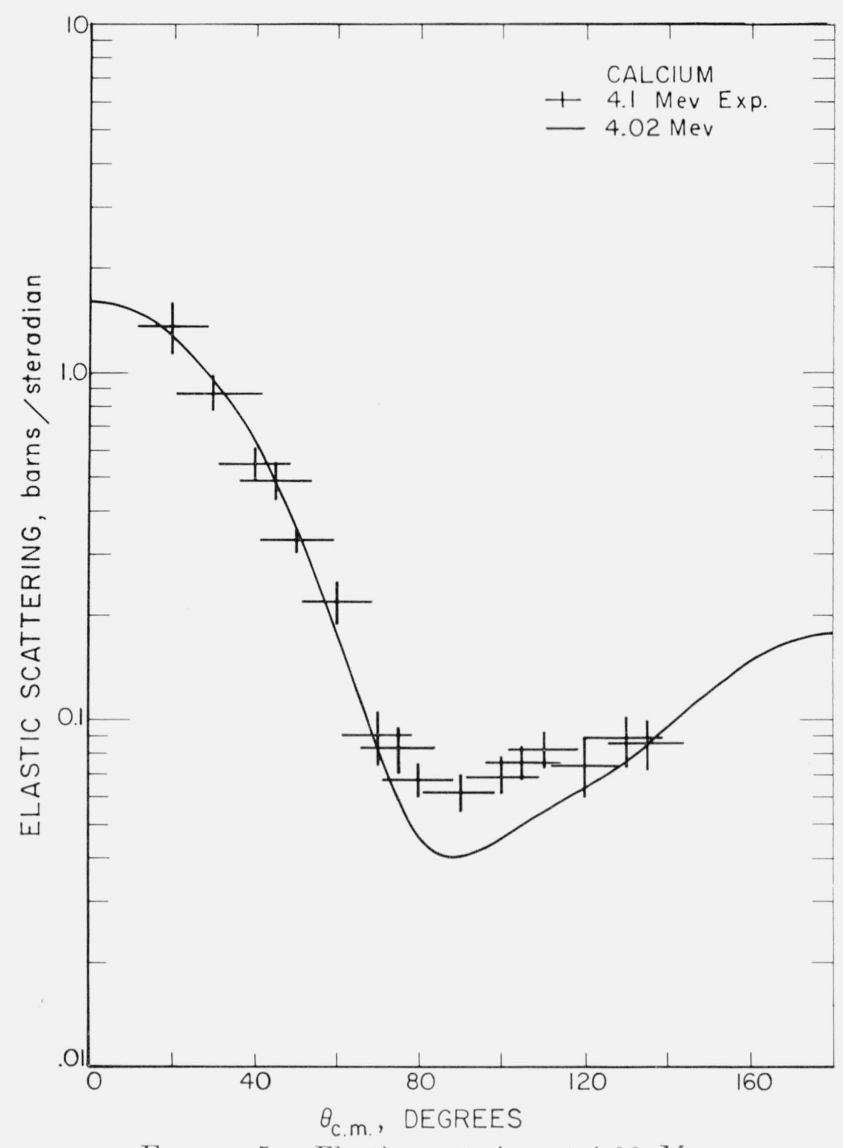

Figure 5. Elastic scattering at $4.02 \mathrm{Mev}$.

The calculation is compared to the $4.1 \mathrm{Mev}$ experimental data of Vincent, The calculation is compared to the
Morgan, and Prud'homme [1960].

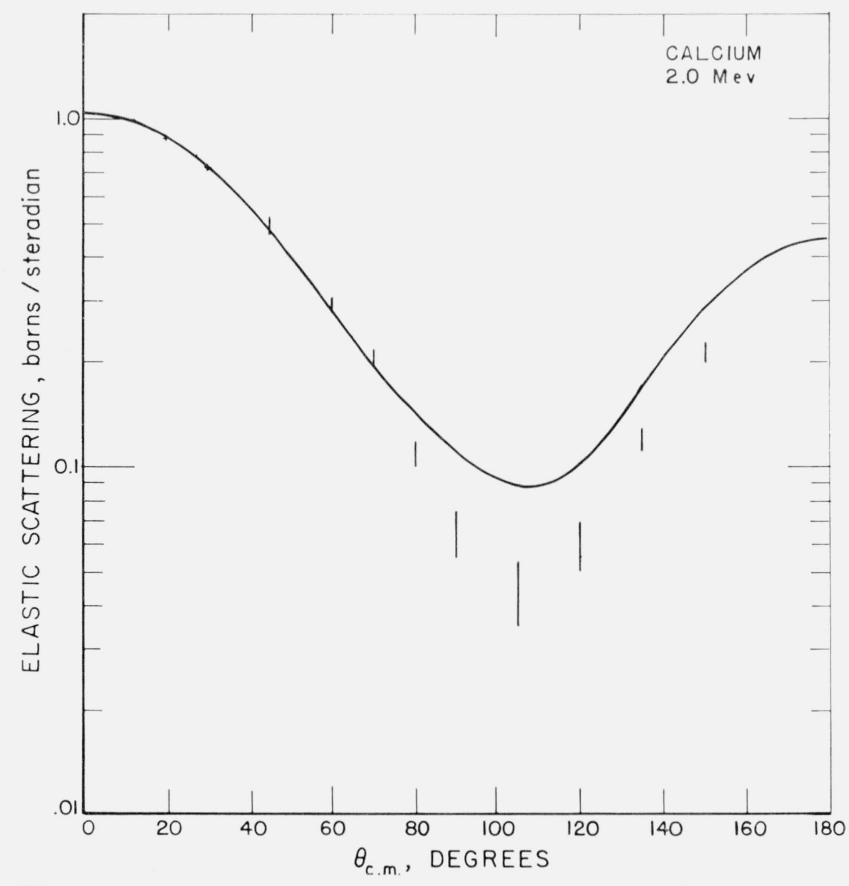

$\rightarrow$ Figure 6. Elastic scattering at $2.0 \mathrm{Mev}$.

Experimental data are from Seagrave, Cranberg, and Simmons (1958). 


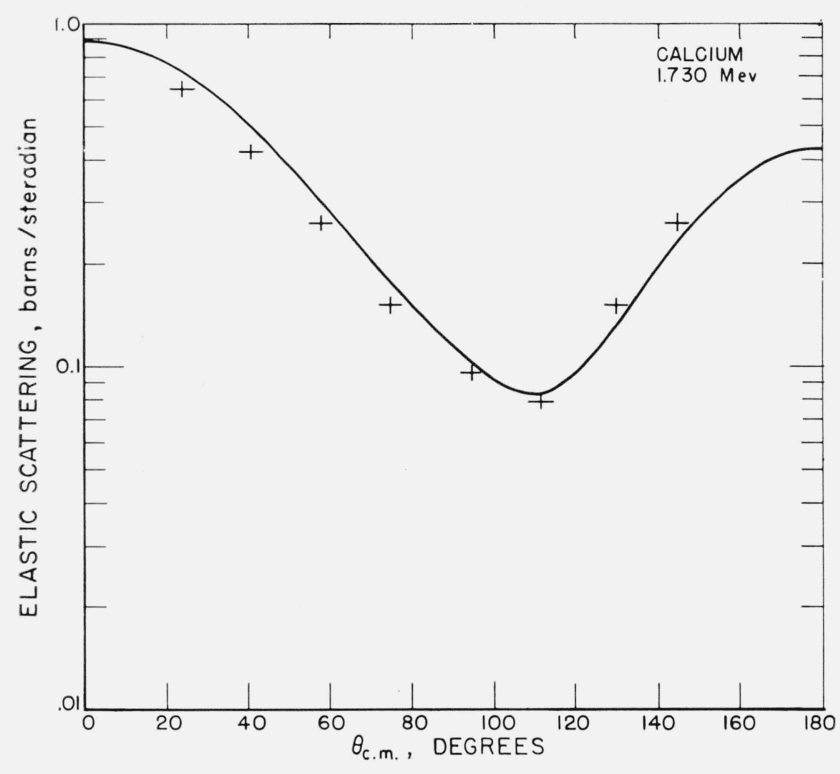

Figure 7. Elastic scattering at 1.730 Mev.

Experimental data are from Lane, Lane, Langsdorf, Monahan, and Elwyn 1960].

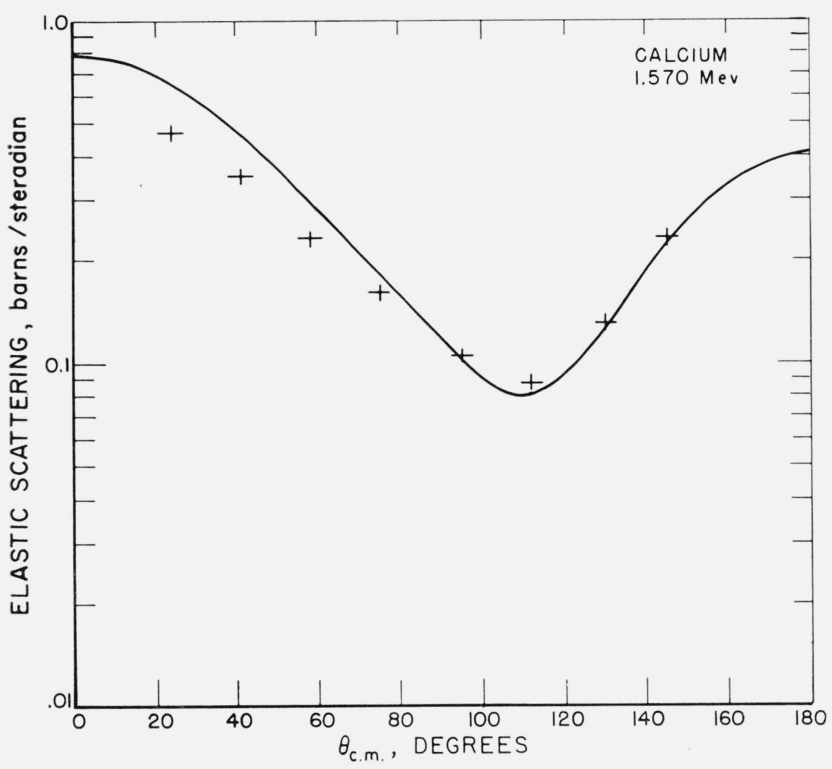

Figure 8. Elastic scattering at $1.5 \% 0 \mathrm{Mev}$.

Experimental data are from Lane, Langsdorf, Monahan, and Elwyn [1960].

1.227 barns at $14.6 \mathrm{Mev}$, whereas the experimental measurement at $14.5 \mathrm{Mev}$ of Flerov and Talyzin [1956] gives $1.36 \pm 0.02$ barns. This leads to a corresponding error in the total cross section, but does not affect the elastic cross section values. The total elastic cross section at $14.6 \mathrm{Mev}$ is 0.803 barns, in agreement with the experimental value of 0.82 \pm 0.07 barns of Cross and Jarvis.

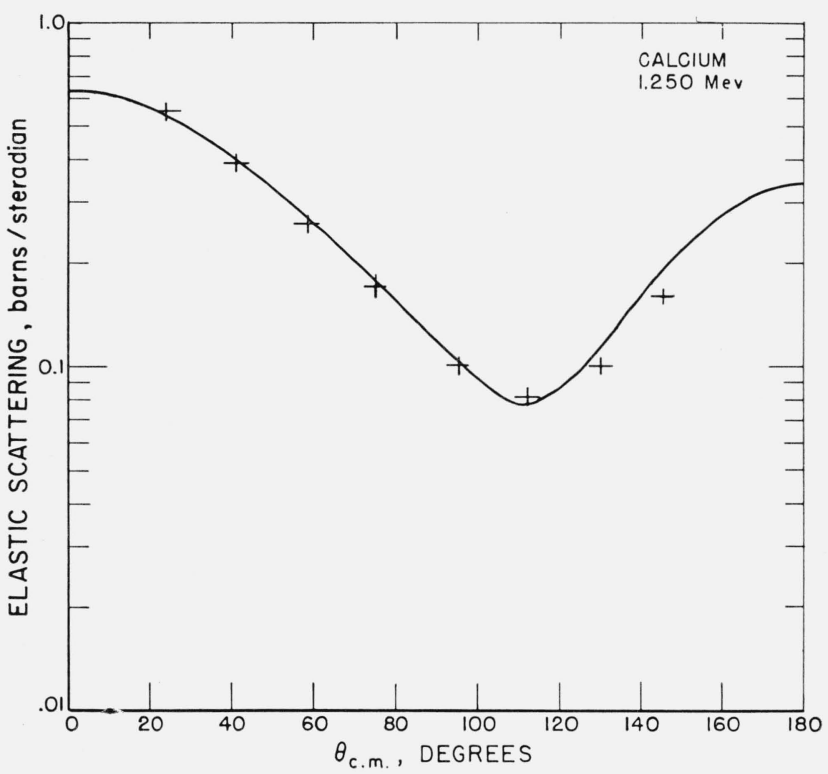

Figure 9. Elastic scattering at 1.250 Mev.

Experimental data are from Lane, Langsdorf, Monahan, and Elwyn [1960].

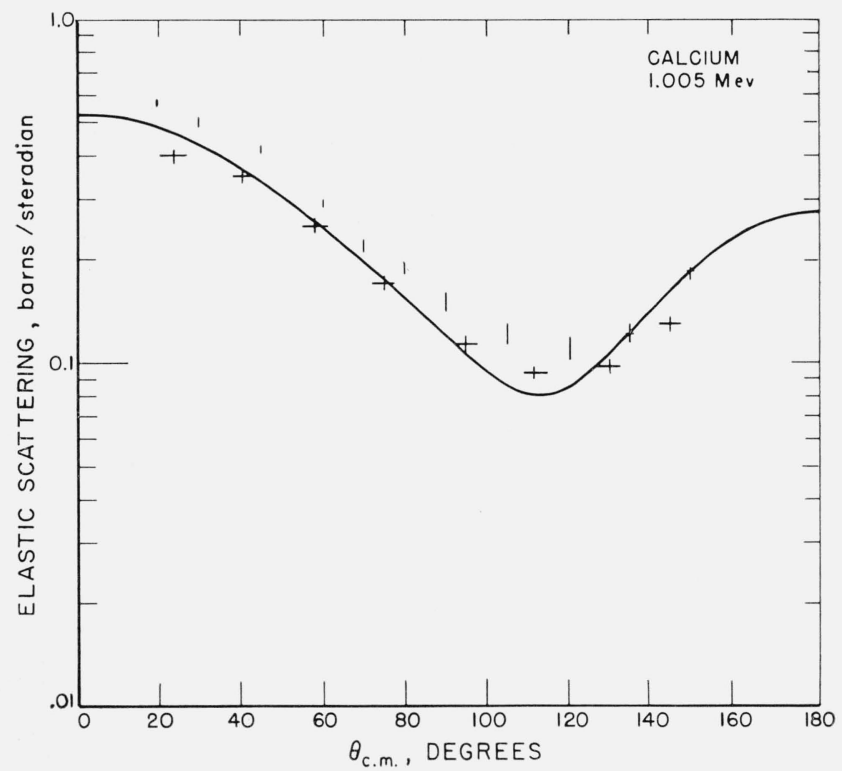

Figure 10. Elastic scattering at $1.005 \mathrm{Mev}$.

Experimental data are from Lane, Langsdorf, Monahan, and Elwyn [1960] at $1.01+0.03 \mathrm{Mev}$ (crosses) and from Seagrave, Cranberg, and Simmons [1958] at $1.0 \mathrm{Mev}$ (vertical lines).

\section{Results of the Calculation}

The calculated angular distributions for total elastic scattering are given in table 1 and the Legendre coefficient expansions are given in table 2 . 


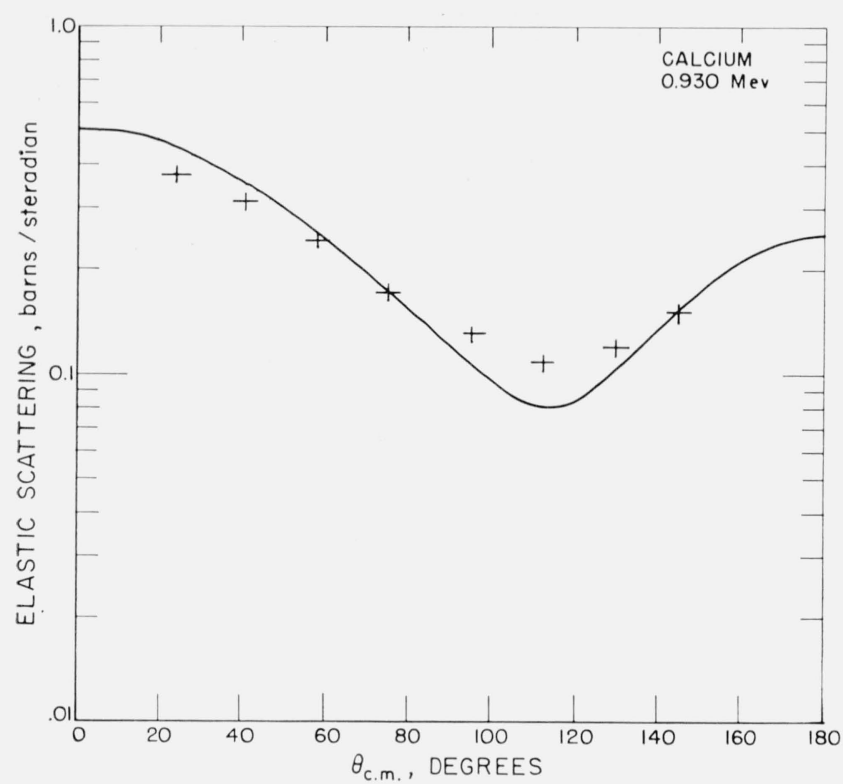

Figure 11. Elastic scattering at $0.930 \mathrm{Mev}$.

Experimental data are from Lane, Langsdorf, Monahan, and Elwyn [1960].

TABLE 1. Angular distributions of neutron elastic scattering for calcium (barns/steradian)

\begin{tabular}{|c|c|c|c|c|c|c|c|}
\hline Angle & $\begin{array}{l}\text { 18. } 000 \\
\text { Mev }\end{array}$ & $\begin{array}{c}\text { 17. } 100 \\
\text { Mev }\end{array}$ & $\begin{array}{c}\text { 16. } 300 \\
\text { Mev }\end{array}$ & $\begin{array}{c}\text { 15. } 500 \\
\text { Mev }\end{array}$ & $\begin{array}{c}14.750 \\
\mathrm{Mev}\end{array}$ & $\begin{array}{c}14.000 \\
\mathrm{Mev}\end{array}$ & $\begin{array}{l}\text { 13. } 300 \\
\mathrm{Mev}\end{array}$ \\
\hline deg & & & & & & & \\
\hline 0. & 2. 2740 & 2. 1727 & 1. 9827 & 1. 8448 & 1. 7511 & 1. 6825 & 1. 5868 \\
\hline 5. 0 & 2. 1104 & 2. 0223 & 1. 8512 & 1. 7277 & 1. 6449 & 1.5857 & 1. 5013 \\
\hline 10.0 & 1. 6774 & 1. 6223 & 1. 4995 & 1. 4131 & 1. 3584 & 1. 3234 & 1. 2685 \\
\hline 15.0 & 1. 1189 & 1. 1011 & 1. 0364 & 0.9947 & 0.9740 & 0.9678 & 0.9495 \\
\hline 20.0 & 0.5980 & 0.6068 & 0.5893 & .5842 & .5908 & .6074 & .6203 \\
\hline 25.0 & .2290 & .2467 & .2544 & .2684 & .2884 & .3147 & .3451 \\
\hline 30.0 & .0439 & .0558 & .0677 & .0837 & & .1262 & 1585 \\
\hline 35.0 & 0031 & .0037 & .0084 & 0161 & 0261 & .0384 & .0614 \\
\hline 40.0 & .0349 & .0270 & .0232 & 0212 & .0208 & .0212 & .0310 \\
\hline 45.0 & .0755 & .0657 & .0582 & .0507 & .0437 & .0366 & .0354 \\
\hline 50.0 & .0914 & .0347 & .0787 & .0712 & 0632 & 45 & .0479 \\
\hline 55.0 & .0792 & .0772 & .0753 & .0712 &.( & 300 & .0533 \\
\hline 60.0 & .0527 & .0540 & .0556 & & .0541 & .0523 & .0484 \\
\hline 65.0 & .0281 & .0302 & .0330 & .0350 & 0366 & .0377 & 0371 \\
\hline 70.0 & 0142 & .0152 & 0175 & .0197 & .0220 & .0237 & .0251 \\
\hline 75.0 & 0112 & .0106 & 0117 & .0123 & .0142 & .0147 & .0162 \\
\hline 80.0 & 0141 & .0127 & 0129 & .0128 & .0127 & .0113 & .0118 \\
\hline 85.0 & 0174 & .0161 & .0161 & .0154 & .0143 & .0117 & .0111 \\
\hline 90.0 & .0178 & .0173 & .0179 & .0174 & .0164 & .0139 & .0130 \\
\hline 95.0 & 0152 & .0156 & .0170 & .0175 & .0175 & .0162 & .0162 \\
\hline 100. & 011 & .01 & .014 & .0160 & .0174 & .0179 & .0194 \\
\hline 105. & .0072 & 0 & 0 & 0 & & .0 & .0217 \\
\hline 110.0 & 0049 & .0061 & .0088 & 0119 & .0152 & .0175 & .0219 \\
\hline 115.0 & .0040 & 0048 & .0072 & 0099 & .0130 & .0150 & .0196 \\
\hline 120.0 & .0039 & .0042 & .0059 & .0079 & .0100 & .0113 & 0150 \\
\hline 125.0 & .0038 & .00 & .004 & .00 & .0067 & .0071 & .0093 \\
\hline 130.0 & .0033 & .003 & 0036 & 0038 & .0041 & .0039 & .0047 \\
\hline 135.0 & .0028 & .002 & .0031 & .0031 & .0030 & .0027 & .0028 \\
\hline 140.0 & .0026 & .0029 & .00 & .0039 & .0041 & .0039 & .0043 \\
\hline 145.0 & .0029 & .0035 & .0048 & .0059 & .0069 & .0071 & .0085 \\
\hline 150.0 & .003 & .00 & .0 & .00 & 0101 & .0105 & .0131 \\
\hline 155.0 & .00 & & & .00 & .0121 & .0126 & .016 \\
\hline 160.0 & .0048 & .0053 & .0075 & .0097 & 0117 & .0122 & 0157 \\
\hline 165.0 & .0049 & .00 & .006 & .007 & .0090 & .0093 & 0120 \\
\hline 170.0 & .0045 & .0039 & .0043 & .0047 & .0051 & .0051 & .0067 \\
\hline 175.0 & .0040 & .0030 & .0026 & .0021 & .0017 & .0015 & .0020 \\
\hline 180.0 & .0038 & .0026 & .0019 & .0010 & .0004 & .0000 & .0001 \\
\hline
\end{tabular}

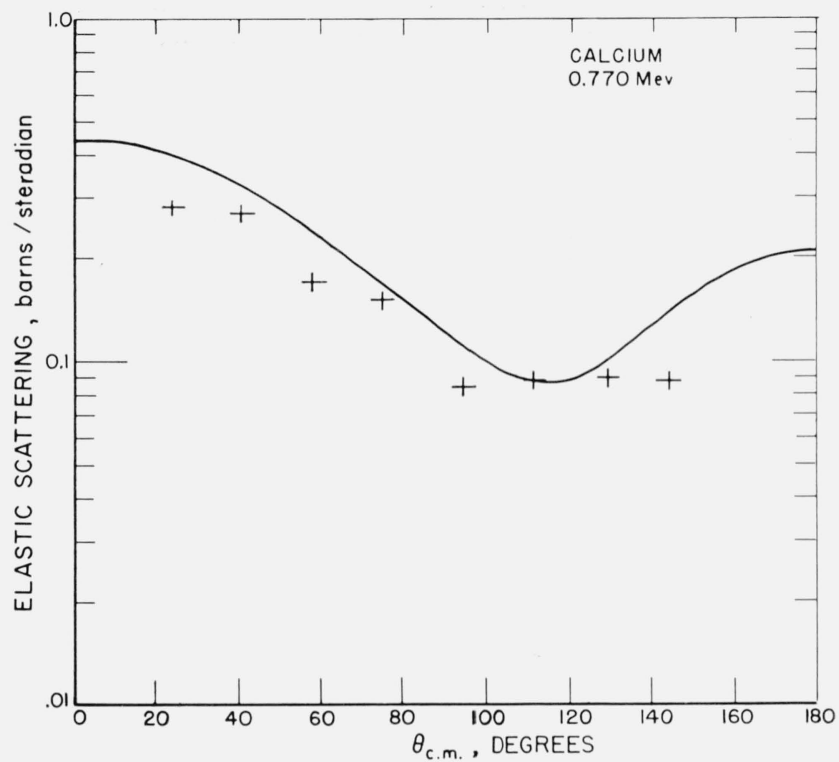

Figure 12. Elastic scattering at $0.7 \% 0 \mathrm{Mev}$.

Experimental data are from Lane, Langsdorf, Monahan, and Elwyn [1960].

TABLE 1. Angular distributions of neutron elastic scattering for calcium (barns/steradian)-Continued

\begin{tabular}{|c|c|c|c|c|c|c|c|}
\hline Angle & $\begin{array}{c}12.700 \\
\text { Mev }\end{array}$ & $\begin{array}{c}12.100 \\
\text { Mev }\end{array}$ & $\begin{array}{c}11.500 \\
\text { Mev }\end{array}$ & $\begin{array}{c}\text { 10. } 900 \\
\mathrm{MeV}\end{array}$ & $\begin{array}{c}\text { 10. } 400 \\
\text { Mev }\end{array}$ & $\begin{array}{l}9.890 \\
\mathrm{Mev}\end{array}$ & $\begin{array}{l}9.410 \\
\text { Mev }\end{array}$ \\
\hline deg & & & & & & & \\
\hline 0. & 1. 5352 & 1. 4533 & 1.4105 & 1. 3773 & 1. 3298 & 1. 3199 & 1. 3476 \\
\hline 5.0 & 1. 4571 & 1. 3852 & 1. 3492 & 1. 3219 & 1. 2816 & 1. 2756 & 1. 3061 \\
\hline 10.0 & 1. 2434 & 1. 1979 & 1. 1794 & 1. 1679 & 1. 1470 & 1. 1511 & 1. 1891 \\
\hline 15.0 & 0.9480 & 0.9357 & 0.9393 & 0.9476 & 0.9521 & 0.9692 & 1. 0165 \\
\hline 20.0 & .6382 & .6555 & .6781 & .7039 & .7321 & .7609 & 0.8159 \\
\hline 25.0 & .3726 & .4078 & .4410 & .4768 & .5212 & .5571 & .6152 \\
\hline 30.0 & .1848 & .2238 & .2577 & .2945 & .3445 & .3815 & .4370 \\
\hline 35.0 & .0792 & .1109 & .1378 & .1684 & .2143 & .2470 & .2946 \\
\hline 40.0 & .0382 & .0573 & .0739 & .0947 & .1302 & .1553 & .1916 \\
\hline 45.0 & .0345 & .0416 & .0489 & .0599 & .0832 & .0997 & .1240 \\
\hline 50.0 & .0434 & .0428 & .0439 & .0480 & .0604 & .0695 & .0830 \\
\hline 55.0 & .0491 & .0459 & .0446 & .0448 & .0497 & .0535 & .0588 \\
\hline 60.0 & .0466 & .0441 & .0428 & .0417 & .0426 & .0431 & .0433 \\
\hline 65.0 & .0373 & .0368 & .0362 & .0352 & .0345 & 0334 & .0312 \\
\hline 70.0 & .0259 & .0268 & .0264 & .0256 & .0247 & .0232 & .0205 \\
\hline 75.0 & .0163 & .0171 & .0164 & .0155 & .0148 & .0134 & .0113 \\
\hline 80.0 & .0105 & .0105 & .0091 & .0079 & .0073 & .0063 & .0051 \\
\hline 85.0 & .0089 & .0079 & .0061 & .0046 & .0042 & .0035 & .0032 \\
\hline 90.0 & .0108 & .0096 & .0078 & .0063 & .0062 & .0057 & .0059 \\
\hline 95.0 & .0148 & .0144 & .0131 & .0119 & .0123 & .0117 & .0121 \\
\hline 100.0 & .0193 & .0205 & .0198 & .0189 & .0202 & .0193 & .0196 \\
\hline 105.0 & 0226 & .0255 & .0254 & .0247 & .0269 & .0257 & .0257 \\
\hline 110.0 & .0233 & .0274 & .0276 & .0271 & .0298 & .0285 & .0284 \\
\hline 115.0 & .0209 & .0252 & .0255 & .0252 & .0281 & .0270 & .0269 \\
\hline 120.0 & .0158 & .0194 & .0197 & .0197 & .0223 & .0218 & .0221 \\
\hline 125.0 & .0097 & .0121 & .0124 & .0127 & .0149 & .0151 & .0158 \\
\hline 130.0 & .0047 & .0059 & .6063 & .0069 & .0086 & .0095 & .0106 \\
\hline 135.0 & .0027 & .0032 & .0035 & .0042 & .0057 & .0067 & .0081 \\
\hline 140.0 & .0042 & .0048 & .0049 & .0053 & .0068 & .0076 & .0090 \\
\hline 145.0 & .0083 & .0096 & .0094 & .0093 & .0109 & .0111 & .0122 \\
\hline 150.0 & .0130 & .0152 & .0146 & .0139 & .0158 & .0152 & .0159 \\
\hline 155.0 & 0159 & .0188 & .0179 & .0168 & .0190 & .0178 & .0182 \\
\hline 160.0 & .0156 & .0186 & .0178 & .0168 & .0188 & .0176 & .0179 \\
\hline 165.0 & .0121 & .0146 & .0143 & .0137 & .0154 & .0145 & .0149 \\
\hline 170.0 & .0070 & .0086 & .0089 & .0090 & .0103 & .0100 & .0106 \\
\hline 175.0 & .0025 & .0034 & .0042 & .0048 & .0058 & .0061 & .0069 \\
\hline 180.0 & .0007 & .0013 & .0023 & .0032 & .0040 & .0046 & .0055 \\
\hline
\end{tabular}


TABLE 1. Angular distributions of neutron elastic scattering for calcium (barns/steradian)-Continued

\begin{tabular}{|c|c|c|c|c|c|c|c|}
\hline Angle & $\begin{array}{l}8.950 \\
\text { Mev. }\end{array}$ & $\begin{array}{l}8.510 \\
\text { Mev. }\end{array}$ & $\begin{array}{l}8.100 \\
\text { Mev. }\end{array}$ & $\begin{array}{l}7.700 \\
\text { Mev. }\end{array}$ & $\begin{array}{l}7.330 \\
\text { Mev. }\end{array}$ & $\begin{array}{l}6.970 \\
\text { Mev. }\end{array}$ & $\begin{array}{l}6.663 \\
\text { Mev. }\end{array}$ \\
\hline deg & & & & & & & \\
\hline 0. & 1. 3531 & 1. 3565 & 1. 3728 & 1. 4119 & 1. 4324 & 1. 4620 & 1. 4826 \\
\hline 5. 0 & 1. 3142 & 1. 3211 & 1. 3389 & 1. 3795 & 1. 4010 & 1. 4320 & 1. 4533 \\
\hline 10.0 & 1. 2039 & 1. 2203 & 1. 2422 & 1. 2867 & 1.3108 & 1. 3456 & 1. 3687 \\
\hline 15.0 & 1.0400 & 1. 0692 & 1. 0962 & 1. 1457 & 1. 1732 & 1. 2131 & 1. 2385 \\
\hline 20.0 & 0.8472 & 0.8887 & 0.9205 & 0.9741 & 1. 0046 & 1. 0491 & 1. 0766 \\
\hline 25.0 & .6513 & .7014 & .7358 & .7911 & 0.8231 & 0.8704 & 0.8990 \\
\hline 30.0 & .4736 & .5265 & .5608 & .6141 & .6457 & .6930 & .7211 \\
\hline 35. 0 & .3276 & .3775 & .4087 & .4565 & .4853 & .5294 & .5554 \\
\hline 40.0 & .2182 & .2603 & .2861 & .3257 & .3500 & .3882 & .4106 \\
\hline 45.0 & .1429 & .1746 & .1939 & .2237 & .2426 & .2731 & .2910 \\
\hline 50.0 & .0946 & .1156 & .1284 & .1485 & .1617 & .1839 & .1972 \\
\hline 55. 9 & .0645 & .0763 & .0835 & .0952 & .1034 & .1180 & .1270 \\
\hline 60.0 & .0450 & .0500 & .0531 & .0585 & .0628 & .0713 & .0768 \\
\hline 65.0 & .0308 & .0316 & .0323 & .0338 & .0356 & .0397 & .0427 \\
\hline 70. 0. & .0193 & .0183 & .0179 & .0175 & .0180 & .0196 & .0211 \\
\hline 75.0 & .0102 & .0090 & .0085 & .0078 & .0078 & .0084 & 0091 \\
\hline 80.0 & .0045 & .0039 & .0036 & .0034 & .0035 & .0039 & .0043 \\
\hline 85.0 & .0030 & .0032 & .0032 & .0037 & .0038 & .0046 & .0048 \\
\hline 90.0 & .0058 & .0065 & .0065 & .0075 & .0076 & .0087 & .0087 \\
\hline 95.0 & .0118 & .0125 & .0123 & .0135 & .0132 & .0145 & .0142 \\
\hline 100.0 & .0188 & .0193 & .0186 & .0196 & .0190 & .0203 & .0197 \\
\hline 105. 0 & .0245 & .0247 & .0236 & .0243 & .0235 & .0247 & .0239 \\
\hline 110. 0 & .0270 & .0271 & .0259 & .0264 & .0255 & .0267 & .0261 \\
\hline 115. 0 & .0258 & .0260 & .0251 & .0257 & .0251 & .0264 & .0262 \\
\hline 120.0 & .0215 & .0223 & .0220 & .0228 & .0229 & .0245 & .0248 \\
\hline 125.0 & .0161 & .0174 & .0179 & .0191 & .0199 & .0219 & .0229 \\
\hline 130.0 & .0116 & 0132 & .0144 & .0161 & .0174 & .0198 & .0213 \\
\hline 135.0 & .0094 & .0112 & .0126 & .0146 & .0162 & .0189 & .0207 \\
\hline 140.0 & .0100 & .0116 & .0129 & .0150 & .0165 & .0193 & .0212 \\
\hline 145.0 & .0127 & .0137 & .0146 & .0165 & .0177 & .0204 & .0222 \\
\hline 150.0 & .0157 & .0162 & .0164 & .0181 & .0189 & .0216 & .0231 \\
\hline 155.0 & .0174 & .0175 & .0173 & .0187 & .0192 & .0218 & .0232 \\
\hline 160.0 & .0168 & .0169 & .0165 & .0178 & .0182 & .0208 & .0223 \\
\hline 165.0 & .0141 & .0143 & .0140 & .0155 & .0160 & .0188 & .0204 \\
\hline 170.0 & .0103 & .0108 & .0109 & .0125 & .0133 & .0163 & .0183 \\
\hline 175.0 & .0071 & .0079 & .0083 & .0101 & .0111 & .0143 & .0165 \\
\hline 180.0 & .0058 & .0067 & .0073 & .0091 & .0103 & .0135 & .0159 \\
\hline Angle & 6.300 & 6.000 & 5.700 & 5.430 & 5.160 & 4.910 & 4.670 \\
\hline & Mev. & Mev. & Mev. & Mev. & Mev. & Mev. & Mev. \\
\hline deg & & & & & & & \\
\hline 0. & 1. 5013 & 1. 5253 & 1. 5377 & 1. 5673 & 1. 5719 & 1. 6092 & 1. 6033 \\
\hline 5.0 & 1. 4726 & 1. 4980 & 1. 5109 & 1. 5411 & 1. 5464 & 1. 5837 & 1. 5786 \\
\hline 10.0 & 1. 3897 & 1. 4188 & 1. 4335 & 1. 4651 & 1. 4723 & 1. 5096 & 1. 5064 \\
\hline 15.0 & 1. 2617 & 1. 2958 & 1. 3128 & 1. 3464 & 1. 3563 & 1. 3935 & 1. 3932 \\
\hline 20.0 & 1. 1018 & 1. 1409 & 1. 1604 & 1. 1956 & 1. 2087 & 1. 2453 & 1. 2483 \\
\hline 25.0 & 0.9254 & 0. 9681 & 0.9894 & 1. 0255 & 1. 0414 & 1. 0770 & 1. 0832 \\
\hline 30.0 & .7473 & .7910 & .8134 & 0.8489 & 0.8669 & 0.9006 & 0.9097 \\
\hline 35.0 & .5799 & .6219 & .6439 & .6774 & .6966 & .7276 & .7387 \\
\hline 40.0 & .4321 & .4697 & .4902 & .5202 & .5395 & .5671 & .5792 \\
\hline 45.0 & .3086 & .3398 & .3580 & .3835 & 4019 & .4254 & .4377 \\
\hline 50.0 & .2105 & .2345 & .2497 & .2704 & .2872 & .3065 & .3181 \\
\hline 55.0 & .1363 & .1531 & .1654 & .1813 & .1961 & .2113 & .2218 \\
\hline 60.0 & .0828 & .0935 & .1031 & .1149 & .1276 & .1392 & .1481 \\
\hline 65.0 & .0463 & .0524 & .0597 & .0683 & .0791 & .0877 & .0951 \\
\hline 70.0 & .0231 & .0262 & .0318 & .0383 & .0474 & .0538 & .0598 \\
\hline 75.0 & .0102 & .0117 & .0160 & .0213 & .0290 & .0340 & .0386 \\
\hline 80.0 & .0049 & .0058 & .0093 & .0139 & .0206 & .0247 & .0282 \\
\hline 85.0 & .0050 & .0060 & .0089 & .0132 & .0191 & .0227 & .0252 \\
\hline 90.0 & .0086 & .0098 & .0122 & .0166 & .0218 & .0250 & .0268 \\
\hline 95.0 & .0138 & .0152 & .0173 & .0217 & .0265 & .0295 & .0306 \\
\hline 100.0 & .0190 & .0207 & .0225 & .0271 & .0317 & .0344 & .0352 \\
\hline 105.0 & .0231 & .0249 & .0268 & .0315 & .0361 & .0388 & .0395 \\
\hline 110.0 & .0255 & .0274 & .0295 & .0344 & .0393 & .0422 & .0430 \\
\hline 115.0 & .0260 & .0282 & .0307 & .0359 & .0412 & .0447 & .0459 \\
\hline 120.0 & .0252 & .0277 & .0309 & .0364 & .0423 & .0468 & .0486 \\
\hline 125.0 & .0239 & .0267 & .0305 & .0363 & .0429 & .0489 & .0515 \\
\hline 130.0 & .0229 & .0259 & .0302 & .0363 & .0435 & .0515 & .0551 \\
\hline 135. 0 & .0227 & .0256 & .0304 & .0368 & .0446 & .0551 & .0597 \\
\hline 140.0 & .0233 & .0261 & .0311 & .0378 & .0460 & .0595 & .0653 \\
\hline 145.0 & .0242 & .0270 & .0322 & .0390 & .0477 & .0649 & .0719 \\
\hline 150.0 & .0251 & .0278 & .0332 & .0403 & .0494 & .0707 & .0791 \\
\hline 155.0 & .0252 & .0280 & .0337 & .0411 & .0508 & .0767 & .0864 \\
\hline 160.0 & .0244 & .0276 & .0336 & .0414 & .0516 & .0824 & .0934 \\
\hline 165.0 & .0229 & .0265 & .0329 & .0411 & .0519 & .0872 & .0994 \\
\hline 170.0 & .0210 & .0252 & .0319 & .0406 & .0518 & .0910 & .1042 \\
\hline 175. 0 & .0196 & .0241 & .0311 & .0401 & .0517 & .0933 & .1072 \\
\hline 180. 0 & .0190 & .0237 & .0308 & .0399 & .0516 & .0941 & .1082 \\
\hline
\end{tabular}

TABLE 1. Angular distributions of neutron elastic scattering for calcium (barns/steradian) - Continued

\begin{tabular}{|c|c|c|c|c|c|c|c|}
\hline Angle & $\begin{array}{l}4.440 \\
\text { Mev }\end{array}$ & $\begin{array}{l}4.230 \\
\text { Mev }\end{array}$ & $\begin{array}{l}4.020 \\
\text { Mev }\end{array}$ & $\begin{array}{l}3.820 \\
\text { Mev }\end{array}$ & $\begin{array}{l}3.640 \\
\text { Mev }\end{array}$ & $\begin{array}{l}3.460 \\
\text { Mev }\end{array}$ & $\begin{array}{l}3.290 \\
\text { Mev }\end{array}$ \\
\hline $\begin{array}{r}\text { deg } \\
0 . \\
5.0 \\
10.0 \\
15.0 \\
20.0\end{array}$ & $\begin{array}{l}1.7219 \\
1.6938 \\
1.6118 \\
1.4832 \\
1.3190\end{array}$ & $\begin{array}{l}\text { 1. } 6126 \\
\text { 1. } 5889 \\
\text { 1. } 5197 \\
\text { 1. } 4109 \\
1.2710\end{array}$ & $\begin{array}{l}\text { 1. } 5996 \\
\text { 1. } 5765 \\
\text { 1. } 5093 \\
\text { 1. } 4034 \\
1.2672\end{array}$ & $\begin{array}{l}\text { 1. } 6072 \\
\text { 1. } 5836 \\
\text { 1. } 5150 \\
\text { 1. } 4077 \\
\text { 1. } 2712\end{array}$ & $\begin{array}{l}\text { 1. } 3986 \\
\text { 1. } 3787 \\
\text { 1. } 3208 \\
\text { 1. } 2298 \\
\text { 1. } 1132\end{array}$ & $\begin{array}{l}\text { 1. } 5570 \\
\text { 1. } 5360 \\
1.4746 \\
\text { 1. } 3776 \\
1.2522\end{array}$ & $\begin{array}{l}1.5703 \\
1.5497 \\
1.4896 \\
1.3944 \\
1.2711\end{array}$ \\
\hline $\begin{array}{l}25.0 \\
30.0 \\
35.0 \\
40.0 \\
45.0\end{array}$ & $\begin{array}{r}1.1321 \\
0.9366 \\
.7455 \\
.5696 \\
.4170\end{array}$ & $\begin{array}{r}1.1107 \\
0.9408 \\
.7719 \\
.6126 \\
.4698\end{array}$ & $\begin{array}{r}1.1109 \\
0.9449 \\
.7794 \\
.6229 \\
.4818\end{array}$ & $\begin{array}{r}1.1161 \\
0.9528 \\
.7907 \\
.6370 \\
.4971\end{array}$ & $\begin{array}{r}0.9799 \\
.8394 \\
.7006 \\
.5708 \\
.4559\end{array}$ & $\begin{array}{r}1.1074 \\
0.9525 \\
.7966 \\
.6475 \\
.5115\end{array}$ & $\begin{array}{r}1.1283 \\
0.9751 \\
.8206 \\
.6726 \\
.5375\end{array}$ \\
\hline $\begin{array}{l}50.0 \\
55.0 \\
60.0 \\
65.0 \\
70.0\end{array}$ & $\begin{array}{l}.2923 \\
.1972 \\
.1304 \\
.0884 \\
.0665\end{array}$ & $\begin{array}{l}.3475 \\
.2477 \\
.1703 \\
.1138 \\
.0754\end{array}$ & $\begin{array}{l}.3602 \\
.2604 \\
.1823 \\
.1247 \\
.0850\end{array}$ & $\begin{array}{l}.3749 \\
.2727 \\
.1915 \\
.1312 \\
.0900\end{array}$ & $\begin{array}{l}.3592 \\
.2824 \\
.2250 \\
.1854 \\
.1607\end{array}$ & $\begin{array}{l}.3927 \\
.2936 \\
.2148 \\
.1552 \\
.1129\end{array}$ & $\begin{array}{l}.4195 \\
.3208 \\
.2421 \\
.1822 \\
.1390\end{array}$ \\
\hline $\begin{array}{l}75.0 \\
80.0 \\
85.0 \\
90.0 \\
95.0\end{array}$ & $\begin{array}{l}.0589 \\
.0600 \\
.0648 \\
.0691 \\
.0702\end{array}$ & $\begin{array}{l}.0519 \\
.0396 \\
.0352 \\
.0358 \\
.0390\end{array}$ & $\begin{array}{l}.0600 \\
.0464 \\
.0408 \\
.0404 \\
.0428\end{array}$ & $\begin{array}{l}.0651 \\
.0524 \\
.0479 \\
.0476 \\
.0491\end{array}$ & $\begin{array}{l}.1475 \\
.1421 \\
.1409 \\
.1410 \\
.1401\end{array}$ & $\begin{array}{l}.0850 \\
.0685 \\
.0602 \\
.0574 \\
.0579\end{array}$ & $\begin{array}{l}.1098 \\
.0917 \\
.0817 \\
.0774 \\
.0768\end{array}$ \\
\hline $\begin{array}{l}100.0 \\
105.0 \\
110.0 \\
115.0 \\
120.0\end{array}$ & $\begin{array}{l}.0668 \\
.0590 \\
.0481 \\
.0363 \\
.0261\end{array}$ & $\begin{array}{l}.0432 \\
.0475 \\
.0514 \\
.0552 \\
.0591\end{array}$ & $\begin{array}{l}.0464 \\
.0504 \\
.0545 \\
.0587 \\
.0636\end{array}$ & $\begin{array}{l}.0511 \\
.0534 \\
.0567 \\
.0616 \\
.0684\end{array}$ & $\begin{array}{l}.1366 \\
.1301 \\
.1204 \\
.1083 \\
.0948\end{array}$ & $\begin{array}{l}.0601 \\
.0634 \\
.0675 \\
.0725 \\
.0791\end{array}$ & $\begin{array}{l}.0783 \\
.0813 \\
.0855 \\
.0912 \\
.0990\end{array}$ \\
\hline $\begin{array}{l}125.0 \\
130.0 \\
135.0 \\
140.0 \\
145.0\end{array}$ & $\begin{array}{l}.0201 \\
.0201 \\
.0277 \\
.0430 \\
.0654\end{array}$ & $\begin{array}{l}.0637 \\
.0693 \\
.0762 \\
.0846 \\
.0942\end{array}$ & $\begin{array}{l}.0694 \\
.0765 \\
.0852 \\
.0956 \\
.1075\end{array}$ & $\begin{array}{l}.0769 \\
.0865 \\
.0968 \\
.1078 \\
.1198\end{array}$ & $\begin{array}{l}.0808 \\
.0677 \\
.0562 \\
.0474 \\
.0417\end{array}$ & $\begin{array}{l}.0877 \\
.0987 \\
.1126 \\
.1293 \\
.1485\end{array}$ & $\begin{array}{l}.1096 \\
.1239 \\
.1423 \\
.1647 \\
.1907\end{array}$ \\
\hline $\begin{array}{l}150.0 \\
155.0 \\
160.0 \\
165.0 \\
170.0\end{array}$ & $\begin{array}{l}.0933 \\
.1243 \\
.1555 \\
.1839 \\
.2066\end{array}$ & $\begin{array}{l}.1047 \\
.1156 \\
.1261 \\
.1354 \\
.1428\end{array}$ & $\begin{array}{l}1206 \\
.1341 \\
.1473 \\
1592 \\
.1686\end{array}$ & $\begin{array}{l}.1335 \\
.1491 \\
.1662 \\
.1834 \\
.1982\end{array}$ & $\begin{array}{l}.0392 \\
.0397 \\
.0425 \\
.0464 \\
.0505\end{array}$ & $\begin{array}{l}.1696 \\
.1915 \\
.2128 \\
.2319 \\
.2471\end{array}$ & $\begin{array}{l}.2191 \\
.2484 \\
.2765 \\
.3013 \\
.3207\end{array}$ \\
\hline $\begin{array}{l}175.8 \\
180.0\end{array}$ & $\begin{array}{l}2212 \\
.2262\end{array}$ & $\begin{array}{l}.1475 \\
.1491\end{array}$ & $\begin{array}{l}.1747 \\
.1768\end{array}$ & $\begin{array}{l}.2085 \\
.2121\end{array}$ & $\begin{array}{l}.0534 \\
.0545\end{array}$ & $\begin{array}{l}.2568 \\
.2602\end{array}$ & $\begin{array}{l}.3331 \\
.3374\end{array}$ \\
\hline Angle & $\begin{array}{l}2.970 \\
\text { Mev }\end{array}$ & $\begin{array}{l}2.690 \\
\text { Mev }\end{array}$ & $\begin{array}{l}2.440 \\
\text { Mev }\end{array}$ & $\begin{array}{l}2.210 \\
\text { Mev }\end{array}$ & $\begin{array}{l}2.000 \\
\text { Mev }\end{array}$ & $\begin{array}{l}1.810 \\
\text { Mev }\end{array}$ & $\begin{array}{l}1.630 \\
\text { Mev }\end{array}$ \\
\hline $\begin{array}{c}d e g \\
0 . \\
5.0 \\
10.0 \\
15.0 \\
20.0\end{array}$ & $\begin{array}{l}1.4990 \\
1.4793 \\
1.4218 \\
1.3311 \\
1.2143\end{array}$ & $\begin{array}{l}\text { 1. } 3767 \\
\text { 1. } 3603 \\
\text { 1. } 3123 \\
\text { 1. } 2361 \\
\text { 1. } 1369\end{array}$ & $\begin{array}{l}\text { 1. } 2546 \\
\text { 1. } 2405 \\
\text { 1. } 1991 \\
\text { 1. } 1332 \\
\text { 1. } 0473\end{array}$ & $\begin{array}{l}1.1456 \\
1.1334 \\
1.0975 \\
1.0403 \\
0.9656\end{array}$ & $\begin{array}{r}1.0433 \\
1.0327 \\
1.0017 \\
0.9522 \\
.8873\end{array}$ & $\begin{array}{r}0.9309 \\
.9221 \\
.8963 \\
.8552 \\
.8013\end{array}$ & $\begin{array}{r}0.8244 \\
.8173 \\
.7963 \\
.7628 \\
.7187\end{array}$ \\
\hline $\begin{array}{l}25.0 \\
30.0 \\
35.0 \\
40.0 \\
45.0\end{array}$ & $\begin{array}{r}1.0797 \\
0.9364 \\
.7927 \\
.6558 \\
.5311\end{array}$ & $\begin{array}{r}1.0211 \\
0.8957 \\
.7679 \\
.6440 \\
.5290\end{array}$ & $\begin{array}{r}0.9466 \\
.8374 \\
.7253 \\
.6160 \\
.5138\end{array}$ & $\begin{array}{l}.8779 \\
.7822 \\
.6838 \\
.5873 \\
.4964\end{array}$ & $\begin{array}{l}.8111 \\
.7278 \\
.6417 \\
.5569 \\
.4767\end{array}$ & $\begin{array}{l}.7378 \\
.6881 \\
.5958 \\
.5241 \\
.4554\end{array}$ & $\begin{array}{l}.6663 \\
.6083 \\
.5476 \\
.4867 \\
.4280\end{array}$ \\
\hline $\begin{array}{l}50.0 \\
55.0 \\
60.0 \\
65.0 \\
70.0\end{array}$ & $\begin{array}{l}.4219 \\
.3298 \\
.2550 \\
.1962 \\
.1520\end{array}$ & $\begin{array}{l}.4269 \\
.3396 \\
.2682 \\
.2119 \\
.1694\end{array}$ & $\begin{array}{l}.4220 \\
.3426 \\
.2764 \\
.2230 \\
.1814\end{array}$ & $\begin{array}{l}.4142 \\
.3425 \\
.2818 \\
.2321 \\
.1924\end{array}$ & $\begin{array}{l}.4036 \\
.3391 \\
.2839 \\
.2380 \\
.2005\end{array}$ & $\begin{array}{l}.3919 \\
.3349 \\
.2851 \\
.2424 \\
.2065\end{array}$ & $\begin{array}{l}.3731 \\
.3232 \\
.2789 \\
.2403 \\
.2071\end{array}$ \\
\hline $\begin{array}{l}75.0 \\
80.0 \\
85.0 \\
90.0 \\
95.0\end{array}$ & $\begin{array}{l}.1201 \\
.0988 \\
.0858 \\
.0795 \\
.0782\end{array}$ & $\begin{array}{l}.1387 \\
.1175 \\
.1036 \\
.0949 \\
.0900\end{array}$ & $\begin{array}{l}.1500 \\
.1268 \\
.1102 \\
.0986 \\
.0908\end{array}$ & $\begin{array}{l}.1614 \\
.1376 \\
.1196 \\
.1061 \\
.0962\end{array}$ & $\begin{array}{l}.1704 \\
.1465 \\
.1276 \\
.1127 \\
.1013\end{array}$ & $\begin{array}{l}.1767 \\
.1520 \\
.1315 \\
.1148 \\
.1015\end{array}$ & $\begin{array}{l}.1787 \\
.1544 \\
.1337 \\
.1163 \\
.1019\end{array}$ \\
\hline $\begin{array}{l}110.0 \\
115.0 \\
120.0\end{array}$ & $\begin{array}{l}.0848 \\
.0908 \\
.0981 \\
.1068\end{array}$ & $\begin{array}{l}.0879 \\
.0882 \\
.0910 \\
.0968 \\
.1063\end{array}$ & & & $\begin{array}{l}.0933 \\
.0889 \\
.0885 \\
.0930 \\
.1032\end{array}$ & $\begin{array}{l}.0916 \\
.0856 \\
.0841 \\
.0878 \\
.0974\end{array}$ & $\begin{array}{l}.0909 \\
.0837 \\
.0811 \\
.0839 \\
.0926\end{array}$ \\
\hline $\begin{array}{l}125.0 \\
130.0 \\
135.0 \\
140.0 \\
145.0\end{array}$ & $\begin{array}{l}.1316 \\
.1498 \\
.1727 \\
.2006\end{array}$ & $\begin{array}{l}.1202 \\
.1391 \\
.1632 \\
.1922 \\
.2252\end{array}$ & $\begin{array}{l}.1168 \\
.1375 \\
.1640 \\
.1957 \\
.2315\end{array}$ & $\begin{array}{l}.1181 \\
.1403 \\
.1686 \\
.2025 \\
.2407\end{array}$ & $\begin{array}{l}.1196 \\
.1426 \\
.1720 \\
.2071 \\
.2466\end{array}$ & $\begin{array}{l}.1133 \\
.1358 \\
.1645 \\
.1986 \\
.2367\end{array}$ & $\begin{array}{l}.1078 \\
.1296 \\
.1575 \\
.1905 \\
.2274\end{array}$ \\
\hline $\begin{array}{l}150.0 \\
155.0 \\
160.0 \\
165.0 \\
170.0\end{array}$ & $\begin{array}{l}.2326 \\
.2671 \\
.3015 \\
.3329 \\
.3580\end{array}$ & $\begin{array}{l}.2607 \\
.2967 \\
.3309 \\
.3608 \\
.3841\end{array}$ & $\begin{array}{l}.2698 \\
.3084 \\
.3448 \\
.3765 \\
.4011\end{array}$ & $\begin{array}{l}.2814 \\
.3223 \\
.3608 \\
.3943 \\
.4202\end{array}$ & $\begin{array}{l}.2885 \\
.3305 \\
.3699 \\
.4041 \\
.4304\end{array}$ & $\begin{array}{l}.2770 \\
.3172 \\
.3550 \\
.3877 \\
.4130\end{array}$ & $\begin{array}{l}.2661 \\
.3044 \\
.3400 \\
.3706 \\
.3941\end{array}$ \\
\hline $\begin{array}{l}175.0 \\
180.0\end{array}$ & $\begin{array}{l}.3743 \\
.3800\end{array}$ & $\begin{array}{l}.3988 \\
.4039\end{array}$ & .4220 & $\begin{array}{l}.4366 \\
.4422\end{array}$ & .4529 & $\begin{array}{r}.4290 \\
.4345\end{array}$ & $\begin{array}{r}4089 \\
.4139\end{array}$ \\
\hline
\end{tabular}


TABLE 1. Angular distribution of neutron elastic scattering for calcium (barns/steradian) - Continued

\begin{tabular}{|c|c|c|c|c|c|c|c|}
\hline Angle & $\begin{array}{l}1.480 \\
\text { Mev }\end{array}$ & $\begin{array}{l}1.340 \\
\mathrm{Mev}\end{array}$ & $\begin{array}{l}1.210 \\
\text { Mev }\end{array}$ & $\begin{array}{l}1.096 \\
\text { Mev }\end{array}$ & $\begin{array}{l}0.991 \\
\text { Mev }\end{array}$ & $\begin{array}{l}0.853 \\
\text { Mev }\end{array}$ & $\begin{array}{l}0.734 \\
\text { Mev }\end{array}$ \\
\hline $\begin{array}{l}\text { deg } \\
0 . \\
5.0 \\
10.0 \\
15.0 \\
20.0\end{array}$ & $\begin{array}{r}0.4400 \\
.4365 \\
.4263 \\
.4097 \\
.3879\end{array}$ & $\begin{array}{r}0.6742 \\
.6691 \\
.6541 \\
.6301 \\
.5982\end{array}$ & $\begin{array}{r}0.3484 \\
.3459 \\
.3388 \\
.3273 \\
.3121\end{array}$ & $\begin{array}{r}0.3193 \\
.3172 \\
.3111 \\
.3013 \\
.2883\end{array}$ & $\begin{array}{r}0.2848 \\
.2831 \\
.2780 \\
.2697 \\
.2586\end{array}$ & $\begin{array}{r}0.4682 \\
.4656 \\
.4577 \\
.4450 \\
.4280\end{array}$ & $\begin{array}{r}0.4299 \\
.4277 \\
.4211 \\
.4104 \\
.3960\end{array}$ \\
\hline $\begin{array}{l}25.0 \\
30.0 \\
35.0 \\
40.0 \\
45.0\end{array}$ & & & $\begin{array}{l}.2938 \\
.2733 \\
.2515 \\
.2292 \\
.2071\end{array}$ & $\begin{array}{l}.2726 \\
.2550 \\
.2360\end{array}$ & $\begin{array}{l}.2453 \\
.2302 \\
.2140 \\
.1972 \\
.1802\end{array}$ & $\begin{array}{l}4074 \\
.3842 \\
.3590 \\
.3328 \\
.3063\end{array}$ & $\begin{array}{l}3786 \\
.3588 \\
.3372 \\
.3146 \\
.2915\end{array}$ \\
\hline $\begin{array}{l}50.0 \\
55.0 \\
60.0 \\
65.0 \\
70.0\end{array}$ & $\begin{array}{l}.2131 \\
.1868 \\
.1630 \\
.1418 \\
.1230\end{array}$ & $\begin{array}{l}.3404 \\
.3007 \\
.2646 \\
.2319 \\
.2028\end{array}$ & $\begin{array}{l}.1857 \\
.1655 \\
.1467 \\
.1295 \\
.1139\end{array}$ & $\begin{array}{l}.1778 \\
.1596 \\
.1424 \\
.1264 \\
.1117\end{array}$ & $\begin{array}{l}.1636 \\
.1477 \\
.1325 \\
.1184 \\
.1053\end{array}$ & $\begin{array}{l}.2801 \\
.2548 \\
.2306 \\
.2078 \\
.1865\end{array}$ & $\begin{array}{l}.2685 \\
.2460 \\
.2244 \\
.2038 \\
.1844\end{array}$ \\
\hline $\begin{array}{l}75.0 \\
80.0 \\
85.0 \\
90.0 \\
95.0\end{array}$ & $\begin{array}{r}.1066 \\
.0922 \\
.0797 \\
.0689 \\
0600\end{array}$ & $\begin{array}{l}.1769 \\
.1540 \\
.1338 \\
.1163 \\
.1016\end{array}$ & $\begin{array}{r}.0998 \\
.0871 \\
.0758 \\
.0659 \\
.0576\end{array}$ & $\begin{array}{l}.0983 \\
.0861 \\
.0752 \\
.0656 \\
.0575\end{array}$ & $\begin{array}{l}.0932 \\
.0822 \\
.0723 \\
.0636 \\
.0562\end{array}$ & $\begin{array}{r}.1669 \\
.1489 \\
.1326 \\
.1182 \\
.1060\end{array}$ & $\begin{array}{l}.1664 \\
.1498 \\
.1348 \\
.1215 \\
.1100\end{array}$ \\
\hline
\end{tabular}

TABLE 1.-Angular distribution of neutron elastic scattering for calcium (barns/steradian)-Continued

\begin{tabular}{|c|c|c|c|c|c|c|c|}
\hline Angle & $\begin{array}{l}\text { 1. } 480 \\
\text { Mev }\end{array}$ & $\begin{array}{l}\text { I. } 340 \\
\text { Mev }\end{array}$ & $\begin{array}{l}\text { 1. } 210 \\
\text { Mev }\end{array}$ & $\begin{array}{l}\text { 1. } 096 \\
\text { Mev }\end{array}$ & $\begin{array}{l}0.991 \\
\text { Mev }\end{array}$ & $\begin{array}{l}0.853 \\
\text { Mev }\end{array}$ & $\begin{array}{l}9.734 \\
\text { Mev }\end{array}$ \\
\hline $\begin{array}{c}\text { deg } \\
100.0\end{array}$ & .0530 & . 0902 & .0511 & .0511 & .0503 & 0961 & .1007 \\
\hline 105.0 & .0484 & .0824 & .0465 & .0465 & .0461 & .0889 & .0937 \\
\hline 110.0 & .0464 & .0790 & .0443 & .0441 & .0437 & .0847 & .0894 \\
\hline 115.0 & .0476 & .0805 & .0447 & .0441 & .0435 & .0839 & .0878 \\
\hline 120.0 & .0521 & .0875 & .0480 & .0467 & .0456 & .0866 & .0893 \\
\hline 125.0 & .0603 & .1003 & .0542 & .0519 & .0499 & .0930 & .0937 \\
\hline 130.0 & .0720 & .1188 & .0634 & .0598 & .0565 & .1028 & .1010 \\
\hline 135. 0 & .0872 & .1426 & .0752 & .0699 & .0652 & .1157 & .1108 \\
\hline 140.0 & .1051 & .1709 & .0893 & .0820 & .0755 & .1312 & .1227 \\
\hline 145.0 & .1250 & .2023 & .1049 & .0955 & .0869 & .1484 & .1360 \\
\hline 150.0 & .1459 & .2352 & .1212 & .1095 & 0989 & .1665 & .1501 \\
\hline 155.0 & .1666 & .2677 & .1373 & .1234 & .1108 & .1844 & .1640 \\
\hline 160.0 & .1858 & .2978 & .1523 & .1363 & .1218 & .2010 & .1768 \\
\hline 165.0 & .2022 & .3236 & .1651 & .1473 & .1312 & .2152 & .1879 \\
\hline 170.0 & .2148 & .3435 & .1749 & .1557 & .1384 & .2261 & .1963 \\
\hline 175.0 & .2228 & .3560 & .1810 & .1610 & .1429 & .2329 & .2016 \\
\hline 180.0 & .2255 & .3602 & .1831 & .1628 & .1445 & .2352 & .2034 \\
\hline
\end{tabular}

TABLE 2. Legendre coefficients for calcium elastic scattering

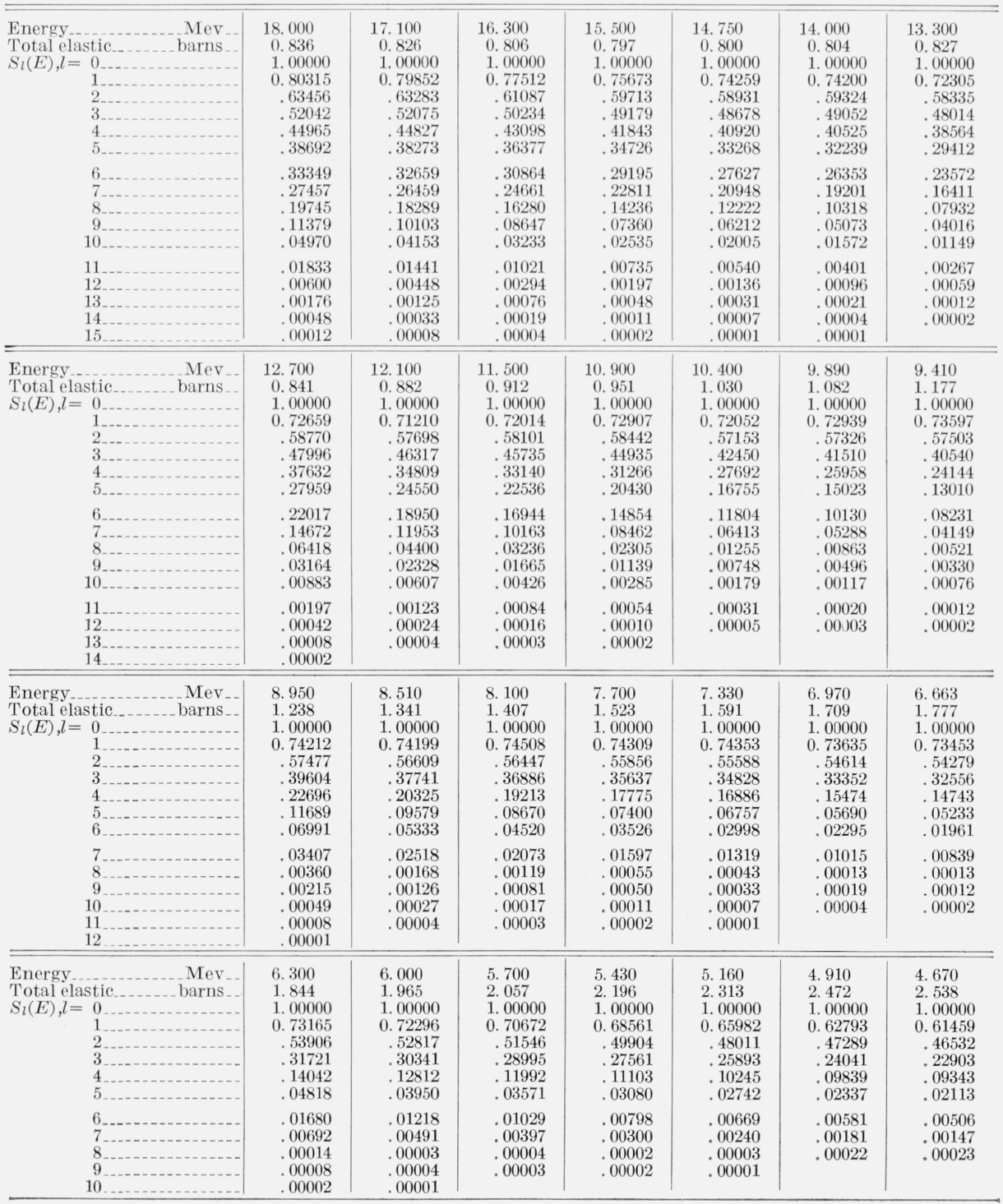


TABLE 2. Legendre coefficients for calcium elastic scattering Continued

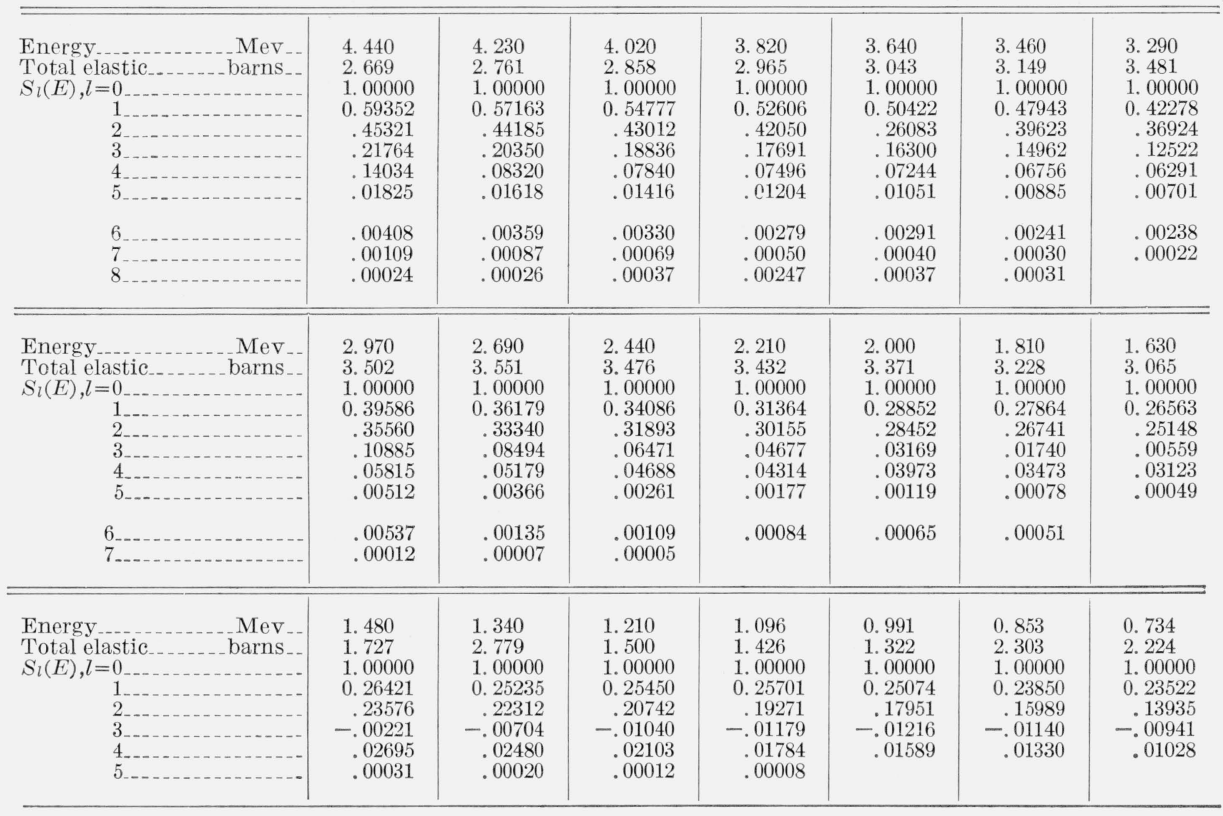

\section{Conclusions}

Reasonably satisfactory average cross section predictions for calcium at neutron energies below $18 \mathrm{Mev}$ can be made with the nuclear optical model using compound elastic scattering cross sections as calculated from the optical model in the absence of inelastic scattering, and using a Hauser-Feshbach calculation if inelastic scattering is present. In order to achieve the goal of calculation of any neutron cross section as required, Hauser-Feshbach and direct interaction inelastic scattering codes for inelastic scattering, and nuclear reaction codes will be required, for which the present type of calculation provides input data.

More experimental data in the region from 6 to 14 $\mathrm{Mev}$ is needed. Also the difference between the Seagrave et al. and the Lane et al. data at low energies needs to be resolved.

\section{References}

Amster, H. J., Leshan, E. J., and Walt, M., Computer techniques, Ch. IV. I., Fast Neutron Physics, Pt I, J. B. Marion and J. L. Fowler, Ed. (1960).

Biedenharn, L. C., U. S. Atomic Energy Commission Report ORNL-1501 (1953).

Biedenharn, L. C., Blatt, J. M., and Rose, M. E., Rev. Mod. Phys. 24, 249 (1952).

Bjorklund, F., and Fernbach, S., Phys. Rev. 109, 1295 (1958).

Blatt, J. M., and Biedenharn, L. C., Rev. Mod. Phys. 24, 258 (1952).

Blatt, J. M., and Weisskopf, V. F., Theoretical Nuclear Physics, p. 333, Wiley (New York) (1952).

Bohm, D., Quantum Theory, p. 344, Prentice-Hall (1951).

Cross, W. G., and Jarvis, R. G., Nuclear Physics 15, 155 (1960).
Edmonds, A. R., Angular Momentum in Quantum Mechanics, Princeton Univ. Press, Princeton, N. J., p. 63 (1957).

Feshbach, H., The complex potential model, Ch. VI. of Nuclear Spectroscopy, Part B, Fay Ajzenberg-Selove, Ed., Academic Press (New York) (1960).

Feshbach, H., Porter, C. E., and Weisskopf, V. F., Phys. Rev. 96, 448 (1954)

Flerov, N. N., and Talyzin, V. M., Atomnaya Energiya 1, 155 (1956)

Gursky, M. L., and Stewart, Leona, Bull. Am. Phys. Soc. II, 6, 367 (1961).

Hauser, W., and Feshbach, H., Phys, Rev, 8\%, 366 (1952).

Howerton, R. J., U. S. A.E.C. Report (UCRL-5573) (1961).

Huber, P., and Mever, K. P., Proc. Intern. Symposium on Polarization Phenomena of Nucleons, p. 436, Berkhaüser Verlag (Basel and Stuttgart) (1961).

Lane, R. O., Langsdorf, A. S. Jr., Monahan, J. B., and Elwyn, A. J., private communication (1960). (See Howerton, 1961.)

Lepore, J., Phys. Rev. 79, 137 (1950)

Morse, P. M., and Feshbach, H., Methods of Theoretical Physics, Mc-Graw Hill, New York, vol. 2, p. 1325 (1953).

Perey, F. G. J., and Buck, B., Neutron Physies Division Progress Report, ORNL-3193 (1961).

Seagrave, J. D., Cranberg, L., and Simmons, J. E., Private communication (1958). (See Howerton, 1961.)

Troubetzkoy, E. S., Kalos, M. H., Lustig, H., Ray, J. H., and Trupin, B. H., NDA Report 2133-4 (NDL-TR-5), Nuclear Development Corporation of America, White Plains, N.Y. (1961).

Vincent, L. D., Morgan, I. L., Prud 'homme, J. T., WADDTR-60-217 (1960).

Whittaker, E. T., and Watson, G. N., Modern Analysis, p. 331, Cambridge (1958).

Wolfenstein, L., Phys. Rev. 82, 690 (1951).

Zurmühl, R., Praktische Mathematik für Ingenieure und Physiker, p. 412, Springer-Verlag, (Berlin, Gottingen, Heidelberg) (1961). 